This document is the accepted manuscript version of the following article:

Hou, Y., Bolat, S., Bornet, A., Romanyuk, Y. E., Guo, H., Moreno-García, P., ... Broekmann, P. (2019). Photonic curing: activation and stabilization of metal membrane catalysts (MMCs) for the electrochemical reduction of CO2. ACs Catalysis, $9(10)$, 9518-9529. https://doi.org/10.1021/acscata1.9b03664

\title{
Photonic Curing: Activation and Stabilization of Metal Membrane Catalysts (MMCs) for the Electrochemical Reduction of $\mathrm{CO}_{2}$
}

Yuhui Hou, ${ }^{\dagger *}$ Sami Bolat, ${ }^{\ddagger}$ Aline Bornet, ${ }^{\dagger}$ Yaroslav E. Romanyuk ${ }^{\ddagger}$, Huizhang Guo, ${ }^{\perp}$ Pavel MorenoGarcía, ${ }^{\dagger}$ Ivan Zelocualtecatl Montiel, ${ }^{\dagger}$ Zhiqiang Lai ${ }^{\dagger}$, Ulrich Müller ${ }^{\xi}$, Vitali Grozovski ${ }^{\dagger}$, and Peter Broekmann ${ }^{\dagger *}$

${ }^{\dagger}$ Department of Chemistry and Biochemistry, University of Bern, Freiestrasse 3, Bern 3012, Switzerland. ${ }^{\ddagger}$ Laboratory of Thin Films and Photovoltaics, Empa - Swiss Federal Laboratories for Materials Science and Technology, Ueberlandstrasse 129, 8600 Dübendorf, Switzerland

${ }^{\perp}$ Wood Materials Science, Institute for Building Materials, ETH Zürich, Stefano-Franscini-Platz 3, 8093 Zürich, Switzerland

${ }^{\xi}$ Nanoscale Materials Science, Empa - Swiss Federal Laboratories for Materials Science and Technology, 8600 Dübendorf, Switzerland.

\begin{abstract}
Photonic curing, an exposure of matter to intense and short ( $\mu \mathrm{s})$ light pulses, is herein demonstrated as an effective and versatile method to activate and stabilize electrocatalysts for the electrochemical reduction of $\mathrm{CO}_{2}$. Catalyst preparation by colloidal synthesis often makes use of surfactants (capping agents) that control the size and morphology of target nano-objects during and after their synthesis. However, this approach can severely compromise the catalytic properties of the as-synthesized nanomaterials. Photonic curing is suitable to gently remove surfactants from the catalyst surface without severely altering its overall structural properties (e.g., surface faceting), thereby increasing the abundance of those surface active sites that can participate in the desired (electro)catalytic reaction. This catalyst activation is exemplarily demonstrated on the basis of $\mathrm{Cu}$ nanowire $(\mathrm{Cu}-\mathrm{NW})$ catalysts synthesized by an oleylamine route and transferred to a glassy carbon (GC) support electrode. Whereas the 3D-networks of the assynthesized $\mathrm{Cu}-\mathrm{NW}$ catalysts predominantly produce hydrogen as product of the electrolysis reaction photonically cured $\mathrm{Cu}-\mathrm{NWs}$, denoted hereinafter as $\mathrm{Cu}$ metal membrane catalysts (MMCs), show a high selectivity towards ethylene formation reaching a Faradaic efficiency of $\mathrm{FE}_{\mathrm{C} 2 \mathrm{H} 4}=42.4 \%\left(\mathrm{~J}_{\mathrm{C} 2 \mathrm{H} 4}=-7.8 \mathrm{~mA}\right.$ $\mathrm{cm}^{-2}, \mathrm{E}=-1.1 \mathrm{~V}$ vs RHE). This high ethylene yield can even be maintained during prolonged electrolysis of $110 \mathrm{~h}$. A further beneficial effect of the photonic curing treatment is related to the substantially increased mechanical stabilization of the $\mathrm{Cu}-\mathrm{NW}$ film on the support electrode induced by a 'mild' sintering of $\mathrm{Cu}-\mathrm{NW}$ which remains locally confined to their points of contact. A loss of catalyst material
\end{abstract}


or a delamination of the catalyst film from the support electrode during massive gas evolution can thus be prevented.

\section{Introduction}

The environmental crisis our society currently faces demands a substantial reduction of greenhouse gas emissions as well as an increase of power generation based on renewable ressources. ${ }^{1}$ In addition, the $\mathrm{CO}_{2}$ already released into the atmosphere needs to be captured and, most preferably, transformed back into value-added products. ${ }^{2-4}$ Among various concepts proposed, it is the electrochemical $\mathrm{CO}_{2}$ reduction reaction (hereinafter referred to as $\mathrm{CO}_{2} \mathrm{RR}$ ) which has the potential to become a technologically and economically feasible approach towards the conversion of $\mathrm{CO}_{2}$ into chemical feedstock, fine chemicals or high energy density fuels ${ }^{5}$ thereby contributing to the future closing of the anthropogenic carbon cycle. ${ }^{6-7}$ This so-called power-to-value concept becomes particularly appealing when the surplus of renewable electricity from wind, solar and hydro sources is exploited. ${ }^{2-3}$ However, the $\mathrm{CO}_{2} \mathrm{RR}$ kinetics and the selectivity towards specific products still needs to be improved to bring the $\mathrm{CO}_{2} \mathrm{RR}$ into an economically feasible industrial application. Substantial efforts have already been made in the development of new $\mathrm{CO}_{2} \mathrm{RR}$ electrocatalysts with tunable particle $s i z \mathrm{e}^{8-9}$, morphology ${ }^{10-11}$, grain-boundary and defect densities $^{12-13}$, to either directly produce value-added products from $\mathrm{CO}_{2}$ (e.g., $\mathrm{C}_{1}-\mathrm{C}_{\mathrm{n}}$ alcohols ${ }^{14-18}$ ) or to obtain reaction intermediates (e.g., $\mathrm{CO}^{19-23}$ ) which can be further converted into hydrocarbons or alcohols in the course of subsequent non-electrochemical reactions (e.g., by Fischer-Tropsch synthesis ${ }^{24}$ or fermentation ${ }^{25}$ ) following the primary $\mathrm{CO}_{2} \mathrm{RR}$.

Not only is the availability of specific active sites (e.g., surface facets or defects) of importance for the resulting $\mathrm{CO}_{2} \mathrm{RR}$ catalyst but also its morphology on various length scales. ${ }^{10-11}$ The particular morphology of the three-dimensional porous catalyst architecture determines the transport characteristics of the reactants into the electroactive material and influences therefore the mean residence time of reaction intermediates (e.g., alkenes ${ }^{10}$ ) inside its porous structure. Note that the probability for reaction intermediates to undergo consecutive reactions (e.g., hydrogenation of unsaturated hydrocarbons) also depends on the catalyst porosity. ${ }^{10-11}$ Further, the three-dimensional structure of the catalyst material needs to be taken into account with regard to the chemical and mechanical stability of the electrode, in particular when high electrolysis current densities (> $200 \mathrm{~mA} \mathrm{~cm}^{-2}$ ) are targeted. Massive gas evolution, e.g. caused by the parasitic hydrogen evolution reaction (HER) superimposed to the $\mathrm{CO}_{2} \mathrm{RR}$ in aqueous reaction media, can induce mechanical stress on the catalyst layer which might lead to its degradation, e.g. by the loss of catalyst material into the electrolyte ${ }^{26}$ or even the complete delamination of the active layer. A bottom-up design of $\mathrm{CO}_{2} \mathrm{RR}$ catalysts controlling the hierarchy of individual structural elements is suited to tackle these challenges. Among others, colloid chemistry can be considered as one promising approach to produce high-surface area electrode materials having a well-defined morphology and 
electrocatalytic properties in terms of an engineering of active sites. ${ }^{27}$ Nonetheless, this colloidal synthesis approach often makes use of organic surfactants controlling nucleation and growth of the desired nanoobjects (e.g., particles, wires etc.), stabilizing thus their shape and preventing undesired precipitation and aggregation during and after their synthesis. ${ }^{28-30}$ However, when left on the catalyst surface these surfactants might compromise the performance of the material by sterically blocking the catalytic active sites. This is why several post-synthesis treatments have been proposed for the surfactant removal, e.g. chemical washing ${ }^{28-29}$, thermal annealing under reductive or inert conditions ${ }^{30}$, exposure to oxidative environments (e.g., $\mathrm{O}_{2}$ plasma or ozone) $)^{9,31}$. However, these approaches often require a non-satisfying long treatment time (e.g., thermal annealing), produce huge amounts of organic waste (chemical washing) or can further alter the surface properties of the catalyst (e.g., plasma treatment ${ }^{32-33}$. The post-synthesis activation of surfactant-stabilized nanocatalysts remains therefore a challenge for the electrode fabrication process.

In this present study we introduce photonic curing as a novel, fast, and versatile alternative to common catalyst activation methods. Note that, in this context, the term catalyst activation primarily refers to the selective removal of the surfactant (capping agent) from the catalyst surface and not to any further structural or compositional alteration of the as-synthesized catalyst material itself. The latter is well known, for instance, from copper-based $\mathrm{CO}_{2} \mathrm{RR}$ catalysts that perform particularly well after being chemically activated by the electroreduction of cupric or cuprous precursor materials. ${ }^{18,34-35}$

Photonic curing, which is often called intense pulse light (IPL) ${ }^{36}$ or flash lamp annealing (FLA) ${ }^{37}$, is based on the exposure of matter to intense light from a xenon flash lamp thereby inducing an ultra-fast local heating of the surface area exposed to these light pulses. This rapidly emerging technology already finds applications in various industrial fields, e.g. in the manufacturing of printed electronic devices as it allows the replacement of glass or ceramic substrates by less expensive and more flexible materials such as polymer sheets or paper. ${ }^{38-39}$ More importantly, photonic curing substantially reduces process times from hours or minutes down to sub-milliseconds. ${ }^{40}$

In this present study, we exemplarily demonstrate the usability of photonic curing for the effective activation of $\mathrm{CO}_{2} \mathrm{RR}$ electrocatalysts by selective surfactant removal. As model system we have chosen highly anisotropic copper nanowires (denoted hereinafter as $\mathrm{Cu}-\mathrm{NWs)}$ which show preferential (100) texturing on their sidewalls. Early studies on single crystalline $\mathrm{Cu}$ catalysts have claimed that the C-C coupling (C2 pathway) is more efficient on (100) textured catalyst, whereas the $\mathrm{C} 1$ hydrocarbon pathway was demonstrated to be preferred on (111) facets. ${ }^{41-43}$ More recent studies utilizing $\mathrm{Cu}$ nanocube-type of catalysts with preferential (100) texturing emphasize the need for an optimized ratio of (100) surface sites and certain edge sites in particular for the formation of ethylene from $\mathrm{CO}_{2}{ }^{8}$ 
For the colloidal synthesis of $\mathrm{Cu}-\mathrm{NWs}$, oleylamine (IUPAC name: (Z)-octadec-9-enylamine, $\mathrm{CH}_{3}\left(\mathrm{CH}_{2}\right)_{7} \mathrm{CH}=\mathrm{CH}\left(\mathrm{CH}_{2}\right)_{7} \mathrm{CH}_{2} \mathrm{NH}_{2}$, denoted in the following as $\left.\mathrm{OAm}\right)$ is often used as organic reaction medium and reducing agent. At the same time it serves as surfactant which selectively stabilizes (100) facets during the anisotropic nanowire growth in solution. ${ }^{44-45}$ The primary amine functionality thereby serves as an anchor group to the $\mathrm{Cu}$ surface.

In what follows, we will demonstrate that photonic curing enables the removal of the OAm surfactant from the catalyst surface without altering the structure of the $\mathrm{Cu}-\mathrm{NWs}$. The performance of the photonic curing approach is compared to other surfactant removal methods, such as thermal annealing, ozone treatment, plasma treatment, and deep UV annealing. To further demonstrate the versatility of photonic curing we will show that this catalyst activation approach is transferable (i) to other catalysts morphologies (e.g. $\mathrm{Cu}$ nanoparticles (Cu-NPs)), (ii) to alternative catalyst materials (e.g. Ag-NWs) and (iii) to other organic surfactants (e.g. polyvinylpyrrolidone). Of equal importance is that photonic curing provides means of mechanically stabilizing the three-dimensional network of $\mathrm{Cu}-\mathrm{NWs}$ which is of particular importance for those electrode processes that involve massive gas evolution (e.g., HER and $\mathrm{CO}_{2} \mathrm{RR}$ from aqueous electrolytes). Li et al. recently described a loss of $\mathrm{Cu}-\mathrm{NW}$ material into the electrolyte under $\mathrm{CO}_{2} \mathrm{RR}$ conditions when drop-casted on a glassy carbon support electrode without any further treatment. ${ }^{26}$ One approach to prevent such mechanical catalyst degradation, proposed by the same authors, is the embedment of Cu-NWs into a carbon black (Ketjen) matrix (catalyst loading $20 \mathrm{wt} \%$ ) that provides sufficient mechanical stability and prevents $\mathrm{Cu}-\mathrm{NW}$ detachment from the electrode. ${ }^{26}$ It should be noted, that the presence of a carbon support exposed to the electrolyte will inevitably affect the resulting Faradaic efficiencies of the electrolysis products. In the latter case, the resulting product distribution originates from superposition of the inherent catalysts characteristics and the contribution of the surrounding carbon matrix (see also supporting information file). On the other hand, photonic curing provides mechanical stability of the three-dimensional network of $\mathrm{Cu}-\mathrm{NWs}$ without the need of a stabilizing carbon matrix. The resulting layer of the activated and stabilized Cu-NWs assembly is denoted hereinafter as $\mathrm{Cu}$ metal membrane catalyst (Cu-MMC).

\section{Experimental}

$\mathrm{Cu}-\mathrm{NW}$ synthesis - $\mathrm{Cu}$ nanowires ( $\mathrm{Cu}-\mathrm{NWs}$ ) were synthesized according to a modified protocol introduced by Guo et al.. ${ }^{46} 0.4 \mathrm{mmol}$ of nickel(II) acetylacetonate (Ni(acac) $)_{2}$, Aldrich, assay 95\%) and 0.8 mmol of copper(II) chloride mono-hydrate $\left(\mathrm{CuCl}_{2} \cdot \mathrm{H}_{2} \mathrm{O}\right.$, Aldrich, assay > 99.99\%) were dissolved in 9 $\mathrm{mL}$ of oleylamine (OAm, Aldrich, assay 70\%) in a three-necked flask. The solution was kept for $10 \mathrm{~min}$ at $100{ }^{\circ} \mathrm{C}$ under strong magnetic stirring conditions and continuous flow of high-purity nitrogen gas (99.995\%, Carbagas, Switzerland). Subsequently, the solution was rapidly heated up to $180{ }^{\circ} \mathrm{C}$ and kept for $3 \mathrm{~h}$ at this temperature. After cooling down to room temperature, an excess of hexane was added to the 
aforementioned solution thus leading to the appearance of a black precipitate which could be isolated by 6 min centrifugation at $4000 \mathrm{rpm}$. The precipitate was thoroughly washed in a mixture of hexane and toluene and subsequently dried in a vacuum oven at $50{ }^{\circ} \mathrm{C}$ for $1 \mathrm{~h}$ yielding a dry powder sample. Afterwards $9 \mathrm{mg}$ of the as-synthesized $\mathrm{Cu}$ nanowires were dispersed in $30 \mathrm{~mL}$ toluene by ultra-sonication. For comparison purposes (see supporting information file) Ag-NWs and $\mathrm{Cu}$ nano-cubes (Cu-NCs) were synthesized also following a colloidal synthesis approach.

Ag-NWs were synthesized according to a modified protocol introduced by da Silva et al. ${ }^{47} 100 \mathrm{mM}$ $\mathrm{AgNO}_{3}$ (Sigma-Aldrich, 99\%) and $50 \mathrm{mM} \mathrm{NaBr}$ (Sigma-Aldrich, 99.99\%) solutions were prepared using ethylene glycol (EG, Acros Organics, 99.5\%) as a solvent. $125 \mathrm{mg}$ poly(vinylpyrrolidone) (PVP, $\mathrm{M}_{\mathrm{r}} \approx$ $1300000 \mathrm{~g} \mathrm{~mol}^{-1}$, Acros Organics) were dissolved in $20 \mathrm{~mL}$ of EG, subsequently heated up to a temperature of $160{ }^{\circ} \mathrm{C}$ and continuously stirred (320 rpm) for $1 \mathrm{~h}$ at this temperature. Subsequently, 250 $\mu \mathrm{L}$ of the $\mathrm{NaBr}$ solution were injected into the reaction vessel. After $15 \mathrm{~min}, 7.5 \mathrm{~mL} \mathrm{AgNO}_{3}$ were dropwise added to the solution at a rate of $0.15 \mathrm{~mL} \mathrm{~min}^{-1}$. After the complete addition of the $\mathrm{AgNO}_{3}$ solution, the reaction mixture was thermally quenched by immersing the reaction vessel into an ice-water bath. After addition of $75 \mathrm{~mL}$ of acetone, the obtained suspension of Ag-NWs was centrifuged. Subsequently, the Ag-NWs were carefully washed with $\mathrm{H}_{2} \mathrm{O}$.

$\mathrm{Cu}-\mathrm{NCs}$ were synthesized according to a modified protocol introduced by Guo et al.. ${ }^{48} 0.3 \mathrm{mmol} \mathrm{CuBr}$ (Acros Organics, 98\%) and $0.5 \mathrm{mmol}$ TOPO (Acros Organics, 99\%) were dissolved at $80^{\circ} \mathrm{C}$ under continuous stirring (15 min at $250 \mathrm{rpm}$ ) in $7 \mathrm{~mL}$ OAm (Sigma-Aldrich, 70\%). This solution was then further heated up to $260{ }^{\circ} \mathrm{C}$ and kept at this temperature under reflux for $2.5 \mathrm{~h}$. After cooling down to room temperature, an excess of toluene was added to the resulting reddish solution. The obtained suspension of $\mathrm{Cu}-\mathrm{NCs}$ was centrifuged at $4000 \mathrm{rpm}$ for $10 \mathrm{~min}$. (Hettich Universal 16). The reddish $\mathrm{Cu}-$ NCs were further purified by five cycles of re-dispersion/centrifugation in a solvent mixture of toluene $(10 \mathrm{~mL})$ and hexane $(1 \mathrm{~mL})$.

Electrode preparation - A standard assembly of $\mathrm{Cu}-\mathrm{NWs}$ was formed by vacuum filtration of $1 \mathrm{~mL}$ of the prepared $\mathrm{Cu}-\mathrm{NW}$ suspension $(0.3 \mathrm{mg} \mathrm{Cu}-\mathrm{NWs} / \mathrm{mL})$ using a Nylon cloth (pore size $0.22 \mu \mathrm{m}$, Fisher Scientific). The resulting $\mathrm{Cu}-\mathrm{NW}$ assembly $(1.2 \mathrm{~cm}$ in diameter) was lifted off from the Nylon cloth in a glass beaker filled with Milli-Q water. While the Nylon cloth membrane dropped down to the bottom of the glass beaker, the lighter and free-standing assembly of $\mathrm{Cu}-\mathrm{NWs}$ remained floating on the surface of the Milli-Q water. With the help of a supporting substrate (e.g., $\mathrm{Cu}$ foil, glassy carbon, carbon cloth, carbon paper, etc.) the $\mathrm{Cu}-\mathrm{NW}$ assembly could be picked up, dried and then further subjected to catalyst activation procedures (e.g., photonic curing, thermal annealing, etc.). Individual steps of the Cu-MMC preparation are shown in Fig. 1. 
For comparison purposes $\mathrm{Cu}-\mathrm{NWs}$ were dispersed also on a technical carbon support (see supporting information file). For the preparation of such carbon-supported $\mathrm{Cu}-\mathrm{NW}$ film, $7.0 \mathrm{mg}$ of the as-prepared $\mathrm{Cu}-\mathrm{NWs}$ were dispersed in $15 \mathrm{~mL}$ of hexane by $1 \mathrm{~h}$ sonication. Further, $3.0 \mathrm{mg}$ of carbon powder (Vulcan $\mathrm{XC}$ 72r, Cabot, USA) were dispersed in $15 \mathrm{~mL}$ of isopropanol by $1 \mathrm{~h}$ sonication. Both suspensions were then intermixed, homogenized by sonication and subsequently dried overnight in vacuum. The thus obtained carbon-supported $\mathrm{Cu}-\mathrm{NWs}$ were re-dispersed in $1.9 \mathrm{~mL}$ of isopropanol (Sigma, assay $\geq 99.5 \%$ ) containing $100 \mu \mathrm{L}$ of Nafion solution (Aldrich, $5 \mathrm{wt} \%$ in lower aliphatic alcohols and water). This suspension was subjected to sonication (probe sonicator, Sonics, probe diameter: $3.2 \mathrm{~mm}$, frequency: 10 $\mathrm{kHz}$ ) for $30 \mathrm{~min}$ thus yielding a homogeneous catalyst ink. $50 \mu \mathrm{L}$ of this ink were then drop-casted and dried on a glassy carbon plate $\left(A=0.8 \mathrm{~cm}^{2}\right.$, Alfa Aesar, $2 \mathrm{~mm}$ thickness, type1). The GC plate had been mirror polished $(0.5 \mu \mathrm{m}$, alumina suspension, Buehler, USA) prior to the drop-casting of the catalyst ink. Activated carbon-supported $\mathrm{Cu}-\mathrm{NWs}$ samples were prepared in the same way. The $\mathrm{Cu}-\mathrm{NWs}$ were, however, subjected to various activation treatments (i.e., thermal annealing, photonic curing, etc.) prior to their dispersion in the hexane solvent.

Catalyst activation - For the photonic curing treatment a PulseForge 1300 system from NovaCentrix was used (xenon flash lamp, optimized conditions: irradiance $5.9 \mathrm{~kW} \mathrm{~cm}^{-2}, 50 \mu$ sulse duration). Light pulses of variable duration in the range from $20 \mu$ s to $150 \mu$ s were applied to the $\mathrm{Cu}-\mathrm{NW}$ assemblies in an inert $\mathrm{N}_{2}$ gas atmosphere thus preventing surface oxidation during the photonic curing. For comparison purposes, the $\mathrm{Cu}-\mathrm{NW}$ assemblies were also subjected to the thermal annealing under protective $\mathrm{N}_{2}$ gas atmosphere using a Nabertherm tube furnace. For the ozone treatment a UV ozone system (PSD Series, Novascan) was used. The total duration of the ozone treatment was $2 \mathrm{~h}$. The ozone chamber was, however, opened every $30 \mathrm{~min}$ to refresh the atmosphere as the oxygen gets consumed during the treatment. For the $\mathrm{N}_{2}$-plasma treatment, the $\mathrm{Cu}-\mathrm{NWs}$ assemblies were activated for $10 \mathrm{~min}$ in a plasma etcher (Plasma Prep III, SPI supplies) at a gas pressure of $300 \mathrm{mT}$ of $\mathrm{N}_{2}$ and a power of $20 \mathrm{~W}$. For the deep UV treatment, the $\mathrm{Cu}-\mathrm{NWs}$ assemblies were exposed to UV light in the deep UV chamber (UV253HRfrom Filgen) for $1 \mathrm{~h}$ under $\mathrm{N}_{2}$ atmosphere.

Electrode characterization - The Cu-NW assemblies were characterized by means of Scanning Electron Microscopy (Zeiss DSM 982). The identical location transmission electron microscopy (IL-TEM) was carried out using a FEI Titan Themis system operated at $300 \mathrm{kV}$. The thickness of the Cu-NW assemblies was determined on the basis of white-light interferometry (ContourGT profilometer, Bruker). The crystallinity of the catalysts was characterized by means of powder X-ray diffraction (XRD) techniques. An STOE Stadi P system with a $\mathrm{Cu} K \alpha$ radiation source $(\lambda=0.1540 \mathrm{~nm}, 40 \mathrm{~mA})$ generated at $40 \mathrm{keV}$ was used. XRD spectra were recorded in reflection mode (Bragg-Brentano geometry) with $2 \theta$ values ranging between 30 and 80 degrees in steps of $1^{\circ} \mathrm{min}^{-1}$. The obtained XRD patterns were analyzed and compared 
to PDF (Powder Diffraction File) standards for Cu. Fourier transform infrared (FTIR) spectra were acquired between 4000 and $400 \mathrm{~cm}^{-1}$ using a FT/IR 4700 spectrometer (Jasco, Germany) in air in an attenuated total reflection (ATR) mode. For this latter measurement, the Cu-MMCs were deposited on glass slides (see Fig. S1).

XPS spectra were acquired on a Physical Electronics (PHI) Quantum 2000 Scanning ESCA Microprobe System using monochromated $\mathrm{Al} \mathrm{K \alpha}$ radiation $(\mathrm{h} v=1486.7 \mathrm{eV})$ and a hemispherical capacitor electronenergy analyzer equipped with a channel plate and a position-sensitive detector. The electron take-off angle was $45^{\circ}$ and the analyzer was operated in the constant pass energy mode at $23.5 \mathrm{eV}$ for the detailed spectra of the $\mathrm{Cu} 2 p_{3 / 2}, \mathrm{O} 1 s, \mathrm{C} 1 s$ and $\mathrm{N} 1 s$ peaks with a step size of $0.20 \mathrm{eV}$. The beam diameter was typically $150 \mu \mathrm{m}$. The binding energy was calibrated using $\mathrm{Cu} 2 p_{3 / 2}, \mathrm{Ag} 3 d_{5 / 2}$ and $\mathrm{Au} 4 f_{7 / 2}$ emissions at $932.62 \mathrm{eV}, 368.21 \mathrm{eV}$, and $83.96 \mathrm{eV}$, respectively to within $\pm 0.1 \mathrm{eV}$. To compensate for eventual surface charging, built-in electron and argon ion neutralizers were used. The base pressure of the system was below $5 \times 10^{-7} \mathrm{~Pa}$. The spectra were analyzed using the software MultiPak 8.2B and peaks are shown after a Shirley background subtraction. The atomic concentrations were calculated using the corrected relative sensitivity factors as given by the manufacturer and normalized to 100 at $\%$. The uncertainty is around $10 \%$ relative.

Electrochemical characterization - $\mathrm{CO}_{2}$ electrolysis experiments were performed using a potentiostat/galvanostat (Metrohm Autolab 302N, The Netherlands) attached to a custom-built, air-tight glass-cell (H-type) which has been described elsewhere. ${ }^{10}$ The current interrupt approach (Autolab Nova, Metrohm) was used to determine the $\mathrm{iR}$ drop (cell resistance). All potentials given herein are iRcompensated. The three-electrode arrangement used consisted of a leakless $\mathrm{Ag} / \mathrm{AgCl} \mathrm{BM}_{3 \mathrm{M}}$ reference electrode $(\mathrm{EDAQ})$, a bright Pt-foil $(15 \mathrm{~mm} \times 5 \mathrm{~mm})$ serving as counter electrode and the glassy carbonsupported $\mathrm{Cu}-\mathrm{MMC}$ catalysts serving as working electrodes. For the sake of comparability, all potentials measured versus $\mathrm{Ag} / \mathrm{AgCl}_{3 \mathrm{M}}$ were referenced with respect to the RHE (reversible hydrogen electrode). Technical details of the $\mathrm{CO}_{2} \mathrm{RR}$ product analysis based on online gas-chromatography (GC) and ion exchange chromatography (IC) have been described elsewhere. ${ }^{10}$ Electrolysis experiments were carried out in $0.5 \mathrm{M} \mathrm{KHCO}_{3}$ (ACS grade, Sigma-Aldrich) electrolyte solutions saturated with $\mathrm{Ar}$ or $\mathrm{CO}_{2}$ gas (99.999\%, Carbagas, Switzerland). Note that, unless otherwise mentioned, a newly prepared catalyst electrode has been used for each $\mathrm{CO}_{2}$ electrolysis experiment.

\section{Results and discussion}

Catalyst activation (surfactant removal) - Fig. 2a-b depicts representative white light interferometric images of the catalyst material that has been transferred after its filtration to a glassy carbon support (see also Fig. 1). This microscopic inspection reveals a rather homogeneous but highly porous catalyst film 
with a root-mean-squared (RMS) roughness of $\mathrm{Rq} \approx 340 \mathrm{~nm}$ (see also Fig. S2). From the corresponding interferometric analysis of the catalyst film edge, a mean layer thickness of $\sim 400 \mathrm{~nm}$ could be determined (panel $\mathrm{c}$ and $\mathrm{d}$ in Fig. 2). Note that the electrode was masked by insulating Teflon tape prior to the $\mathrm{CO}_{2}$ electrolysis so that a defined geometric surface area of $0.8 \mathrm{~cm}^{2}$ was exposed to the electrolyte (Fig. S3). The analysis of the catalyst film by scanning electron microscopy (SEM) shows a three-dimensional network of randomly distributed Cu-NWs (Fig. 3a). Their length can exceed tens of micrometers whereas the nanowire diameter is typically in the range of $50 \mathrm{~nm}-70 \mathrm{~nm}$ (see representative HR-TEM in Fig. 3b). Selective area electron diffraction (SAED) analysis obtained from an individual Cu-NW (Fig. 3c) confirms, in full accordance with the literature, the five-fold twinned face centered cubic (fcc) structure of the $\mathrm{Cu}-\mathrm{NWs}$ and their preferential orientation along the [110] crystallographic direction. ${ }^{49}$ The sidewalls of the $\mathrm{Cu}-\mathrm{NWs}$ consist of 5 (100) textured facets whereas the pentagonal apex of the $\mathrm{Cu}-\mathrm{NW}$ is (111) terminated (Fig. 3d). These (111) facets represent the actual growth front where precursor ions get preferentially reduced and added to the developing nanowire. Earlier studies ${ }^{50}$ suggest a preferential and stronger adsorption of the organic surfactants on the (100) facets thereby sterically blocking these sites for further addition of metal atoms. The anisotropy of the metal growth originates, at least in this scenario, from the weaker surfactant adsorption on the (111) facets thus allowing for the continuous unidirectional addition of metal atoms. More recent studies emphasize, however, the important role of chloride anions for this highly anisotropic growth of $\mathrm{Cu}-\mathrm{NWs}$ in particular when carried out in aqueous solutions. ${ }^{51}$ Note that cupric chloride is typically used as copper source for the $\mathrm{Cu}-\mathrm{NWs}$ growth. Chloride anions tend to strongly chemisorb on $\mathrm{Cu}$ surfaces. ${ }^{52-58}$ Wiley et al. discussed the competitive adsorption of chloride and alkylamine-based surfactants as origin of the anisotropic $\mathrm{Cu}$ growth. Chloride anions were demonstrated to remove the surfactant more effectively from the (111) oriented facets, thereby keeping them active for the metal growth. ${ }^{51}$

The presence of surfactants on the surface of the $\mathrm{Cu}-\mathrm{NWs}$ after the wet chemical synthesis represents a severe drawback for their application as catalysts, due to the active reaction sites being sterically blocked by the surfactants. A mild catalyst activation process is therefore required that selectively removes the surfactant molecules from the NW surfaces while preserving their unique structural properties. In order to identify optimum experimental conditions for the surfactant removal and catalyst activation, $\mathrm{Cu}-\mathrm{NW}$ assemblies were subjected to photonic curing at constant irradiance $\left(5.9 \mathrm{~kW} \mathrm{~cm}{ }^{-2}\right)$ but variable pulse lengths (single pulse approach). The photonic curing was carried out in a nitrogen gas atmosphere to avoid any extra compositional or structural change of the $\mathrm{Cu}-\mathrm{NW}$ s that might go along with oxidation of the nano-material when exposed to oxygen during the photonic treatment. After activation, the resulting catalytic performance was studied by means of $\mathrm{CO}_{2} \mathrm{RR}$ product analysis following one hour potentiostatic electrolysis of a $\mathrm{CO}_{2}$-saturated $0.5 \mathrm{M} \mathrm{KHCO}_{3}$ solution at $-1.1 \mathrm{~V}$ vs. RHE. Results of this pre-screening 
step are presented in Fig. 4a (note that the irradiance dependence was already screened beforehand, see Fig. S4). As expected, the as-prepared $\mathrm{Cu}-\mathrm{NW}$ assemblies show only a minor activity towards $\mathrm{CO}_{2} \mathrm{RR}$. $\mathrm{H}_{2}$, originating from the parasitic HER, is the predominant product of the electrolysis reaction reaching a Faradaic efficiency of $\mathrm{FE}_{\mathrm{H} 2}=73.3 \%\left(\mathrm{~J}_{\mathrm{H} 2}=-13.9 \mathrm{~mA} \mathrm{~cm}{ }^{-2}\right.$. Formate is clearly the main $\mathrm{CO}_{2} \mathrm{RR}$ product with a Faradaic yield of $12.0 \%\left(\mathrm{~J}_{\text {formate }}=-2.3 \mathrm{~mA} \mathrm{~cm}{ }^{-2}\right)$, followed by minor yields of ethylene $\left(\mathrm{FE}_{\mathrm{C} 2 \mathrm{H} 4}=\right.$ $\left.5.1 \%, \mathrm{~J}_{\mathrm{C} 2 \mathrm{H} 4}=-0.97 \mathrm{~mA} \mathrm{~cm}^{-2}\right)$. Also traces of $\mathrm{CO}$ could be detected $\left(\mathrm{FE}_{\mathrm{CO}}=1.9 \%, \mathrm{~J}_{\mathrm{CO}}=-0.36 \mathrm{~mA} \mathrm{~cm}^{-2}\right)$. Note that formate is the least demanding $\mathrm{CO}_{2} \mathrm{RR}$ product with regard to the $\mathrm{Cu}$ catalyst ( $\mathrm{Cu}-\mathrm{O}$ binding) whereas formation of ethylene requires a high abundance of next neighbor adsorption sites that can strongly bind $\mathrm{CO}(\mathrm{Cu}-\mathrm{C}$ binding) thus being a mechanistic prerequisite for subsequent $\mathrm{C}-\mathrm{C}$ coupling reactions. ${ }^{59-60} \mathrm{CO}$ forms as key intermediate in the course of the $\mathrm{CO}_{2}$ electroreduction. In particular the (100) facets, key structural motifs of the NW sidewalls, have been discussed in the literature as active for the C-C coupling reaction. ${ }^{43,60-61}$ The hydrocarbon pathways remain, however, largely suppressed on the non-activated $\mathrm{Cu}-\mathrm{NW}$ electrocatalyst when the OAm surfactant is still present (Fig. 4a).

When considering ethylene as the most valuable $\mathrm{CO}_{2} \mathrm{RR}$ product there is a clear optimum at $50 \mu$ sulse duration (Fig. 4a) resulting in a maximum ethylene efficiency of $\mathrm{FE}_{\mathrm{C} 2 \mathrm{H} 4}=42.4 \%\left(\mathrm{~J}_{\mathrm{C} 2 \mathrm{H} 4}=-7.8 \mathrm{~mA} \mathrm{~cm}^{-2}\right)$, thus being indicative for an effective OAm surfactant removal (for details see Tab. S1). Note that the SEM and HR-TEM analyses in Fig. 3 were carried out after the photonic curing proving that, at least under the given experimental conditions, this activation treatment does not severely affect the structural characteristics of the Cu-NWs. After applying optimum curing conditions, the Faradaic efficiency for $\mathrm{H}_{2}$ production is substantially reduced to $\mathrm{FE}_{\mathrm{H} 2}=32 \%\left(\mathrm{~J}_{\mathrm{H} 2}=-5.9 \mathrm{~mA} \mathrm{~cm}{ }^{-2}\right)$, whereas the total $\mathrm{CO}_{2} \mathrm{RR}$ efficiency reaches $\mathrm{FE}_{\mathrm{CO} 2 \mathrm{RR}}=69 \%\left(\mathrm{~J}_{\mathrm{CO} 2 \mathrm{RR}}=-12.8 \mathrm{~mA} \mathrm{~cm}{ }^{-2}\right)$. More extended photonic curing leads, however, to the gradual drop down of the total $\mathrm{CO}_{2} \mathrm{RR}$ efficiencies, e.g. $\mathrm{FE}_{\mathrm{CO} 2 \mathrm{RR}}=34 \%\left(\mathrm{~J}_{\mathrm{CO} 2 \mathrm{RR}}=-5.8 \mathrm{~mA}\right.$ $\mathrm{cm}^{-2}$ ) when pulses of $150 \mu$ s duration are applied (Fig. 4a). This trend can be regarded as an experimental hint for an undesired structural degradation of the $\mathrm{Cu}-\mathrm{NW}$ catalyst taking place upon prolonged photonic curing times at the given irradiance of $5.9 \mathrm{~kW} \mathrm{~cm}^{-2}$. This conclusion is consistent with an SEM inspection of the photonically cured $\mathrm{Cu}-\mathrm{MMCs}$ demonstrating that the $50 \mu$ s photonic curing at $5.9 \mathrm{~kW} \mathrm{~cm}^{-2}$ does not induces structural changes of the $\mathrm{Cu}-\mathrm{NW}$ assembly on larger macroscopic length scales or on the length scale of individual Cu-NWs (Fig. S5). By contrast, prolonged photonic curing times lead to severe structural alterations of the Cu-NWs (Fig. S6a). As a result, semi-hemispheric droplets appear on the NW sidewalls. Similar morphological and structural changes were observed after thermal annealing at temperatures $\geq 300^{\circ} \mathrm{C}$ (Fig. S6b). One might assume that these substantial structural changes also involve a decrease in the relative abundance of those specific surface sites needed for the $\mathrm{C}$-C coupling. 
Fig. $4 \mathrm{~b}$ displays the complete potential dependent $\mathrm{CO}_{2} \mathrm{RR}$ product analysis for the optimum photonic curing conditions $\left(50 \mu \mathrm{s}, 5.9 \mathrm{~kW} \mathrm{~cm}{ }^{-2}\right)$. A maximum of $\mathrm{FE}_{\mathrm{C} 2 \mathrm{H} 4}=42.4 \%\left(\mathrm{~J}_{\mathrm{C} 2 \mathrm{H} 4}=-7.8 \mathrm{~mA} \mathrm{~cm} \mathrm{~cm}^{-2}\right)$ is observed for an electrolysis potential of $-1.1 \mathrm{~V}$ vs RHE that is anti-correlated with the minimum in the Faradaic efficiency for hydrogen production $\left(\mathrm{FE}_{\mathrm{H} 2}=32.0 \%, \mathrm{~J}_{\mathrm{H} 2}=-5.9 \mathrm{~mA} \mathrm{~cm}{ }^{-2}\right)$. At higher overpotentials, e.g. at -1.2 vs RHE, the hydrogen efficiency starts to increase $\left(\mathrm{FE}_{\mathrm{H} 2}=41.3 \%, \mathrm{~J}_{\mathrm{H} 2}=-10.2 \mathrm{~mA} \mathrm{~cm}{ }^{-2}\right)$ at the expense of the ethylene yield $\left(\mathrm{FE}_{\mathrm{C} 2 \mathrm{H} 4}=35.6 \%, \mathrm{~J}_{\mathrm{C} 2 \mathrm{H} 4}=-8.8 \mathrm{~mA} \mathrm{~cm}{ }^{-2}\right)$. Note that this trend does not necessarily point to the loss of catalytic performance of the $\mathrm{Cu}-\mathrm{MMC}$ at higher overpotentials but might, instead, be ascribed to the onset of $\mathrm{CO}_{2}$ mass transport limitations in quiescent aqueous electrolytes where the $\mathrm{CO}_{2}$ solubility is limited to $\sim 35 \mathrm{mM} .^{3,6}$ The high reproducibility of the electrode preparation and catalyst activation procedure is demonstrated in Fig. S7 showing the $\mathrm{CO}_{2} \mathrm{RR}$ product distribution of five independent electrolysis experiments performed at $-1.1 \mathrm{~V}$ vs RHE.

Comparable or even higher ethylene efficiencies than the one achieved in this present study were already reported in the literature. ${ }^{8,34,61-63}$ E.g., Mistry et al. obtained an ethylene selectivity of $\mathrm{FE}_{\mathrm{C} 2 \mathrm{H} 4} \approx 60 \%$ at comparably low overpotentials of $-0.9 \mathrm{~V}$ vs RHE. These extraordinarily high $\mathrm{C}_{2} \mathrm{H}_{4}$ yields are typically observed only when using so-called oxide-derived (OD) $\mathrm{Cu}$ catalysts. Facile approaches to activate $\mathrm{Cu}$ based $\mathrm{CO}_{2} \mathrm{RR}$ catalysts by oxidation are the exposure to oxygen plasma, thermal annealing in air ${ }^{64-65}$, or electrode anodization ${ }^{35}$. These formed cupric and cuprous oxides typically get reduced under $\mathrm{CO}_{2} \mathrm{RR}$ conditions thereby creating those low-coordinated sites and grain boundaries which are particularly active for hydrocarbon or alcohol formation ${ }^{15}$. An extra activation of the $\mathrm{Cu}-\mathrm{NW}$ catalyst, e.g., by surface oxidation, was excluded herein as the photonic curing was carried out in inert $\mathrm{N}_{2}$ atmosphere (see experimental section). Further chemical activation of the Cu-MMCs will be treated separately in a forthcoming study.

It is interesting to note that no substantial ethane formation is observed for the Cu-MMC catalyst (Fig. 4b). From porous $\mathrm{Cu}$ foam catalysts it is known that, due to the prolonged residence time of the intermediates inside the three-dimensional catalyst, formed ethylene gets, to some extent, further reduced to ethane as consequence of re-adsorption and subsequent reduction steps. The $\mathrm{Cu}$ foam catalysts, studied by Dutta et al. ${ }^{10}$, show a primary macro-porosity with pore sizes on the mirco-meter length scale and a secondary porosity of their dendritic sidewalls on the nm length scale. These previous studies indicate that the electrolyte can penetrate into the $\mu \mathrm{m}$-sized macro-pores of the $\mathrm{Cu}$ foams giving rise to a pronounced poresize dependence of the resulting $\mathrm{CO}_{2} \mathrm{RR}$ product distribution. ${ }^{10}$

The absence of ethane in the present case (Fig. 4b) can be regarded as first experimental hint for an electrolyte which does not completely penetrate the entire three-dimensional network of the $\mathrm{Cu}-\mathrm{NWs}$. Apparently, the wetting of the $\mathrm{Cu}-\mathrm{MMC}$ remains confined to the outermost volume of the 3D network of $\mathrm{Cu}-\mathrm{NWs}$. To support this hypothesis we carried out two extra control experiments. The first one was 
based on a thickness variation of the Cu-MMC (see Fig. S2, S8 and S9). The $\mathrm{CO}_{2} \mathrm{RR}$ product distribution is found to be largely insensitive to the further increase of the $\mathrm{Cu}-\mathrm{NW}$ layer thickness (Fig. S8a). A slight increase of the $\mathrm{H}_{2}$ efficiency was, however, observed when the Cu-MMC thickness was further reduced (Fig. S8a). This latter observation might point to a certain contribution of the glassy carbon substrate to the resulting $\mathrm{CO}_{2} \mathrm{RR}$ product distribution when the MMC thickness falls below a critical value (Fig. S8b). Exchanging the glassy carbon support of the $\mathrm{Cu}-\mathrm{MMC}$ by an $\mathrm{Ag}$ foil does not lead to a substantial alteration of the $\mathrm{CO}_{2} \mathrm{RR}$ product distribution provided the $\mathrm{Cu}-\mathrm{MMC}$ layer thickness is sufficiently high (Fig. S10a). These control experiments are indicative for an electrolysis reaction that takes place within a spatially confined and constant volume of the three-dimensional $\mathrm{Cu}-\mathrm{MMC}$ as illustrated in Fig. S8b and S10b.

For comparison purposes, we present in Fig. S11 a similar potential-dependent product analysis for $\mathrm{Cu}-$ MMC samples treated by thermal annealing in an inert nitrogen gas atmosphere at $200{ }^{\circ} \mathrm{C}$. Also this approach leads to certain catalyst activation but on a significantly lower level as compared to the photonic curing (Fig. 4a-b). A maximum of $\mathrm{FE}_{\mathrm{C} 2 \mathrm{H} 4}=15.5 \%\left(\mathrm{~J}_{\mathrm{C} 2 \mathrm{H} 4}=-2.5 \mathrm{~mA} \mathrm{~cm}{ }^{-2}\right)$ is yielded after the $2 \mathrm{~h}$ annealing at $200{ }^{\circ} \mathrm{C}$. Obviously, there is no clear preference for $\mathrm{C}-\mathrm{C}$ coupled hydrocarbons after the thermal annealing, no matter what annealing times have been applied. Methane efficiencies are, however, comparably high after the thermal treatment, e.g. $\mathrm{FE}_{\mathrm{CH} 4}=9.2 \%$ at $-1.1 \mathrm{~V}$ vs RHE (Fig. S11). A C2/C1 hydrocarbon ratio of $\sim 1.7$ clearly points to poor product selectivity towards ethylene. In case of the catalyst activated by photonic curing the respective $\mathrm{C} 2 / \mathrm{C} 1$ hydrocarbon ratio at $-1.1 \mathrm{~V}$ vs RHE electrolysis potentials is 12.1 (Fig. 4b). Annealing temperatures above $200{ }^{\circ} \mathrm{C}$ lead to a further decrease of the $\mathrm{CO}_{2} \mathrm{RR}$ performance most likely due to structural catalyst degradation as observed in the SEM analysis (Fig. S6b).

A more complete overview over the performance of different surfactant removal approaches is provided in Fig. 5 that includes thermal annealing, the exposure of the catalyst to ozone, deep UV treatment and plasma activation. Among these, it is indeed the photonic curing which demonstrates the most promising results, in particular when ethylene is targeted as $\mathrm{CO}_{2} \mathrm{RR}$ product. It can be hypothesized that the observed differences in the $\mathrm{CO}_{2} \mathrm{RR}$ performance are due to different efficiencies in the OAm surfactant removal. To support this hypothesis surface-sensitive XPS analyses were carried out after applying the activation treatments to the $\mathrm{Cu}-\mathrm{NW}$ catalyst films (Fig. 6). The ratio of the integrated $\mathrm{N} 1 s$ and $\mathrm{Cu} 2 p_{3 / 2}$ intensities can be considered as a measure for the effectiveness of the respective surfactant removal. As expected, the as prepared sample shows the highest $\mathrm{N} 1 s: \mathrm{Cu} 2 p_{3 / 2}$ ratio followed by the thermally annealed one. This observation is fully consistent with the non-satisfying $\mathrm{CO}_{2} \mathrm{RR}$ performance of the as-prepared and annealed catalyst samples (Fig. 5 and S11). A more efficient surfactant removal is observed for the plasma and ozone treatments. Obviously, the photonic curing and the deep UV treatment lead to an 
almost complete surfactant removal (Fig. 6b). The comparison of Fig. 4 and 5 demonstrates a qualitatively reasonable correlation between the surfactant removal, probed by XPS via the $\mathrm{N} 1 s: \mathrm{Cu} 2 p_{3 / 2}$ ratio, and the resulting $\mathrm{CO}_{2} \mathrm{RR}$ performance. An effective surfactant removal is further confirmed by the IR inspection of the photonically cured Cu-MMC sample (Fig. S12).

It should be emphasized at this point that the catalyst activation by photonic curing is highly versatile and not limited to $\mathrm{Cu}$-based materials. Photonic curing can be applied to other colloidal systems prepared by various surfactant-assisted synthesis routes. As an example we present in the supporting information file analogous investigations on Ag-NWs synthesized by the assistance of polyvinylpyrrolidone (PVP). Their selectivity towards $\mathrm{CO}$ formation can substantially be improved by applying the novel photonic curing activation method (see Fig. S13). These supporting experiments further demonstrate that the surfactant removal is not only limited to monomeric OAm surfactants but can be successfully applied also to polymeric capping agents (e.g., PVPs). Furthermore, the catalyst activation by photonic curing is also transferable to other catalyst morphologies, e.g. shaped nanoparticles (see Fig. S14).

Catalyst stability - Not only are the product selectivity and the achieved partial $\mathrm{CO}_{2} \mathrm{RR}$ current densities of importance for the evaluation of the overall catalyst performance but also the mechanical robustness and the long-term chemical stability of the electrode assembly.

In order to demonstrate the superior mechanical stability of the photonically cured Cu-MMCs optical micorgraphs were taken before and after $1 \mathrm{~h} \mathrm{CO}_{2} \mathrm{RR}$ at $-1.1 \mathrm{~V}$ vs RHE (Fig. 7). Gas evolution reactions (e.g., HER and $\mathrm{CO}_{2} \mathrm{RR}$ ) can induce substantial mechanical stress to the electrode assembly particularily when exposed to an aqueous environment. This stress often leads to a loss of active catalyst material into the solution phase during the electrolysis reaction ${ }^{26}$ or even to a partial or complete delamination of the catalst layer from the support electrode. Delamination phenomena upon $\mathrm{CO}_{2} \mathrm{RR}$ are observed in particular for the as-prepared $\mathrm{Cu}-\mathrm{NW}$ sample and the thermally annealed one whereas substantial losses of catalyst material into the solution phase become apparent from the optical micrographs of those samples treated by deep UV light and by ozone exposure (Fig. 7). The only catalyst sample which obviously remains unaffected by the $\mathrm{CO}_{2} \mathrm{RR}$ at $-1.1 \mathrm{~V}$ vs RHE is the photonically cured one (repective repitition experiments are shown in Fig. S15). This observation is also consitent with an identical location microscopic inspection of the photonically cured $\mathrm{Cu}-\mathrm{MMC}$ prior to and after the $\mathrm{CO}_{2} \mathrm{RR}$ not showing any severe morphological alterations after the electrolysis reaction at $-1.1 \mathrm{~V}$ vs RHE (Fig. S16). Such mechanical stabilization is most likely achieved by the 'mild' sintering of the $\mathrm{Cu}-\mathrm{NW}$ upon photonic curing which remains locally confined to their points of contact, at least for the given curing conditions $(50 \mu \mathrm{s}, 5.9 \mathrm{~kW}$ $\mathrm{cm}^{-2}$ ). Further, the photonic curing not only improves the rigidity of the $3 \mathrm{D} \mathrm{Cu}-\mathrm{NW}$ assembly itself. It also improves the adhesion to the underlying support material (e.g., to the glassy carbon electrode). 
Massive losses of $\mathrm{Cu}-\mathrm{NW}$ material into the electrolyte during the electrolysis, as reported by Li et al. ${ }^{26}$, can thus be prevented even without using a stabilizing carbon matrix (e.g., Vulcan, Ketjn; Nafion) .

With regard to the structural stability on a nanometer scale, nanowire-based catalysts seem to be superior over nanoparticles of the same catalyst material (see Fig. S17). Cube-shaped Cu-NPs of similar diameter as the $\mathrm{Cu}-\mathrm{NWs}$ studied herein undergo comparably fast structural degradation involving the loss of the extended and preferential (100) texturing upon $\mathrm{CO}_{2} \mathrm{RR}$ (Fig. S17). ${ }^{66}$ This might be an important finding for the application of $\mathrm{CO}_{2} \mathrm{RR}$ catalysts under industrial conditions where their reliability is key.

At this point the question arises whether the observed trend in the $\mathrm{CO}_{2} \mathrm{RR}$ performace (Fig. 5) can soley be ascribed to differences in the OAm removal efficiency as concluded from Fig. 6 or weather extra effects due to the observed degradation phenomena (Fig. 7) also contribute, at least to some extent, to the resulting $\mathrm{CO}_{2} \mathrm{RR}$ product distribution. In particular the delamination of the $\mathrm{Cu}-\mathrm{NW}$ films from the glassy carbon support will necessarily lead to a certain contribution of the support material to the overall electrolysis reaction. As the glassy carbon support electrode is active only towards the HER an increase of the $\mathrm{FE}_{\mathrm{H} 2}$ is indeed expected. However, cyclic voltammetric control experiments carried out in the Arsaturated and $\mathrm{CO}_{2}$-saturated $0.5 \mathrm{M} \mathrm{KHCO}_{3}$ solution (Fig. S18) clearly demonstrate a comparably low activity of the glassy carbon electrode towards the HER at the relevant electrolysis potential of $-1.1 \mathrm{~V}$ vs RHE. From this control experiment we therefore conclude that the main contribution to the $\mathrm{FE}_{\mathrm{H} 2}$ in case of the as-prepared and thermally annealed samples (Fig. 5) originates from the inefficient removal of surfactants from the $\mathrm{Cu}$ catalyst surface with only minor contributions from the glassy carbon support after the partial delamination of the catalyst film.

Further, to avoid the undesired strcutural degradation processes at elevated current densities (Fig. 7) selected $\mathrm{CO}_{2}$ electrolysis experiemnts were carried out also at $-0.8 \mathrm{~V}$ vs RHE. Due to the reduced overall curent densities at $-0.8 \mathrm{~V}$ vs RHE in the order of $\sim 2.5 \mathrm{~mA} \mathrm{~cm}{ }^{-2}$ all the pretrated catalyst films remain structurally intact as evidenced by the optical inspection shown in Fig. S19a. Important to note is that also at these lower overpotentials the same trend of an improved $\mathrm{CO}_{2} \mathrm{RR}$ performance is observed after the photonic curing treatment (Fig. S19b) as already seen for the electrolysis at -1.1 V vs RHE (Fig. 5). The comparably higher Faradaic efficiency towards hydrogen in case of the thermally annealed sample can solely be ascribed to an insuffiecient surfactant removal whereas undesired side effects originating from the glassy carbon support after partial delamination of the catalyst layer can be excluded in this case (Fig. S19b) .

An alternative route to avoid losses of catalyst material into the aqueous electrolyte phase dunring the electrolysis reation is the embedment of $\mathrm{Cu}-\mathrm{NWs}$ into a carbon support matrix as recently discussd by $\mathrm{Li}$ et al.. ${ }^{26}$ Also in this case the photonic curing of the $\mathrm{Cu}-\mathrm{NWs}$, carried out prior to the catalyst ink preparation, leads to to a further improvement of the $\mathrm{CO}_{2} \mathrm{RR}$ performance (Fig. S20). It should be 
however, noted that catalyst films based on C-supported $\mathrm{Cu}-\mathrm{NWs}$ predominantly yield methane as major hydrocarbon product of the $\mathrm{CO}_{2} \mathrm{RR}$ in full agreement with the recent work by $\mathrm{Li}$ et al.. ${ }^{26}$ This observation again points to the fact that the resulting $\mathrm{CO}_{2} \mathrm{RR}$ product distribution is not soley governed by the intrinsic structural properties of the catalyst material on the atomic scale (e.g., (100) versus (111) surface faceting) but, as already pointed out by Dutta et al. ${ }^{10}$, results from the complex convolution of several effects involving also the catalyst film morphology on various length scales which affects the local reaction environment (e.g., local $\mathrm{pH}$ ) and the reactant/product transport characteristics inside the threedimensional catalyst material.

To further demonstrate the superior chemical stability of the photonically cured $\mathrm{Cu}-\mathrm{MMC}$ an extended $110 \mathrm{~h}$ lasting $\mathrm{CO}_{2}$ electrolysis has been carried out at an applied potential of $-1.1 \mathrm{~V}$ vs RHE (Fig. 8). Within this period of electrolysis time the ethylene efficiency remains well above $>40 \%$. At least on this time scale there is no noticeable catalyst degradation. The photonically cured $\mathrm{Cu}-\mathrm{MMC}$ also withstands stressing experiments where the electropotential is periodically switched from the OCP to $-1.1 \mathrm{~V}$ vs RHE (Fig. S21).

When using (polycrystalline) Cu catalysts, it is often the coupled C1/2 hydrocarbon pathway (Figure 9) which causes a fast and irreversible catalyst degradation. ${ }^{15}$ According to early work by Hori et al. ${ }^{67}$, Akhade et al. ${ }^{68}$ and Dewulf et al. ${ }^{69}$, hydrocarbon formation might involve an irreversible chemisorption of ${ }^{*} \mathrm{C}$ surface species on the catalyst surface, which blocks those sterically demanding reactive sites that are required for the ${ }^{*} \mathrm{CH}_{2}$ dimerization. ${ }^{15}$ More recent DFT results by Nie et al ${ }^{70}$ discuss $\mathrm{C} 1$ and $\mathrm{C} 2$ pathways that also share key intermediates such as ${ }^{*} \mathrm{CO},{ }^{*} \mathrm{COH}$ and ${ }^{*} \mathrm{CH}_{2}$ but do not involve the formation of poisoning $* \mathrm{C}$ species. The long term stability of the photonically cured $\mathrm{Cu}-\mathrm{MMC}$ catalyst suggests that both methane and ethylene formation occur in the present case rather via the ${ }^{*} \mathrm{COH}$ route ${ }^{70}$ than via the ${ }^{*} \mathrm{C}$ pathway. The latter would lead to an irreversible poisoning of the catalyst surface as shown by Rahaman et al. for dendritic $\mathrm{Cu}^{15}$

\section{Conclusions}

Photonic curing in an inert gas atmosphere has been introduced as an effective and highly versatile method to remove surfactants (capping agents) from the surface of stabilized nanomaterials (e.g. nanowires, nanoparticles etc.) thereby activating them for electrocatalytic reactions, e.g. the $\mathrm{CO}_{2}$ electroreduction reaction $\left(\mathrm{CO}_{2} \mathrm{RR}\right)$. Crucial is the right balance of the energy input, depending on factors such as the irradiance $\left(\mathrm{kW} \mathrm{cm}^{-2}\right)$ and the irradiation time (typically in the range of $\mu \mathrm{s}$ ), to remove the surfactant from the as-synthesized catalyst without degrading those structural features (e.g., surface sites) of the nanomaterial that are particularly active towards the targeted (electro)catalytic reaction. One prime example, discussed in detail herein, is the activation of oleylamine stabilized $\mathrm{Cu}-\mathrm{NW}$ s wich yield up to $42 \%$ ethylene as $\mathrm{CO}_{2} \mathrm{RR}$ product at $-1.1 \mathrm{~V}$ vs RHE after applying one single pulse of $50 \mu$ s duration at 5.9 
$\mathrm{kW} \mathrm{cm}{ }^{-2}$ irradiance. Optimized curing conditions depend on the chemical nature of the catalyst material, the support electrode and the capping agent used during synthesis. Photonic curing also leads to a substantial mechanical stabilization of the NW assembly (denoted as metal membrane catalyst: MMC) thus being important in particular for electrocatalytic reactions involving massive gas evolution which can induce mechanical stress to the electrode assembly.

Future method development will focus on multi-step catalyst activation steps, e.g. involving reactive gas environments with the aim to direct the $\mathrm{CO}_{2} \mathrm{RR}$ product distribution towards alcohol formation.

\section{ASSOCIATED CONTENT}

\section{Supporting Information}

The Supporting Information is available free of charge on the ACS Publications website

\section{AUTHOR INFORMATION}

Corresponding Author

*peter.broekmann@dcb.unibe.ch

*yuhui.hou@dcb.unibe.ch

\section{Notes}

The authors declare no competing financial interests.

\section{ACKNOWLEDGMENT}

The financial support by the CTI Swiss Competence Center for Energy Research (SCCER Heat and Electricity Storage) is gratefully acknowledged. PB acknowledges the financial support by the Swiss National Science Foundation (SNSF) via the project No. 200020_172507. This study was performed with the support of the interfaculty Microscopy Imaging Centre (MIC) of the University of Bern. 


\section{References}

1. Qiao, J.; Liu, Y.; Hong, F.; Zhang, J., A review of catalysts for the electroreduction of carbon dioxide to produce low-carbon fuels. Chem. Soc. Rev. 2014, 43 (2), 631-675.

2. Jones, J.-P.; Prakash, G. K. S.; Olah, G. A., Electrochemical $\mathrm{CO}_{2}$ Reduction: Recent Advances and Current Trends. Isr. J. Chem. 2014, 54 (10), 1451-1466.

3. Jhong, H.-R. M.; Ma, S.; Kenis, P. J. A., Electrochemical Conversion of $\mathrm{CO}_{2}$ to Useful Chemicals: Current Status, Remaining Challenges, and Future Opportunities. Curr. Opin. Chem. Eng. 2013, 2 (2), 191-199.

4. Appel, A. M.; Bercaw, J. E.; Bocarsly, A. B.; Dobbek, H.; DuBois, D. L.; Dupuis, M.; Ferry, J. G.; Fujita, E.; Hille, R.; Kenis, P. J. A.; Kerfeld, C. A.; Morris, R. H.; Peden, C. H. F.; Portis, A. R.; Ragsdale, S. W.; Rauchfuss, T. B.; Reek, J. N. H.; Seefeldt, L. C.; Thauer, R. K.; Waldrop, G. L., Frontiers, Opportunities, and Challenges in Biochemical and Chemical Catalysis of $\mathrm{CO}_{2}$ Fixation. Chem. Rev. 2013, 113 (8), 6621-6658.

5. Li, C. W.; Ciston, J.; Kanan, M. W., Electroreduction of carbon monoxide to liquid fuel on oxidederived nanocrystalline copper. Nature 2014, 508 (7497), 504-507.

6. Durst, J.; Rudnev, A.; Dutta, A.; Fu, Y.; Herranz, J.; Kaliginedi, V.; Kuzume, A.; Permyakova, A. A.; Paratcha, Y.; Broekmann, P.; Schmidt, T. J., Electrochemical $\mathrm{CO}_{2}$ Reduction - A critical View on Fundamentals, Materials and Applications. Chimia 2015, 69 (12), 769-776.

7. Whipple, D. T.; Kenis, P. J. A., Prospects of $\mathrm{CO}_{2}$ Utilization via Direct Heterogeneous Electrochemical Reduction. J. Phys. Chem. Lett. 2010, 1 (24), 3451-3458.

8. Loiudice, A.; Lobaccaro, P.; Kamali, E. A.; Thao, T.; Huang, B. H.; Ager, J. W.; Buonsanti, R., Tailoring Copper Nanocrystals towards $\mathrm{C} 2$ Products in Electrochemical $\mathrm{CO}_{2}$ Reduction. Angew. Chem. Int. Ed. 2016, 55 (19), 5789-5792.

9. Reske, R.; Mistry, H.; Behafarid, F.; Roldan Cuenya, B.; Strasser, P., Particle Size Effects in the Catalytic Electroreduction of $\mathrm{CO}_{2}$ on $\mathrm{Cu}$ Nanoparticles. J. Am. Chem. Soc. 2014, 136 (19), 69786986.

10. Dutta, A.; Rahaman, M.; Luedi, N. C.; Mohos, M.; Broekmann, P., Morphology Matters: Tuning the Product Distribution of $\mathrm{CO}_{2}$ Electroreduction on Oxide-Derived Cu Foam Catalysts. ACS Catal. 2016, 6 (6), 3804-3814.

11. Dutta, A.; Rahaman, M.; Mohos, M.; Zanetti, A.; Broekmann, P., Electrochemical $\mathrm{CO}_{2}$ Conversion Using Skeleton (Sponge) Type of Cu Catalysts. ACS Catal. 2017, 7 (8), 5431-5437.

12. Li, J.; Chen, G.; Zhu, Y.; Liang, Z.; Pei, A.; Wu, C.-L.; Wang, H.; Lee, H. R.; Liu, K.; Chu, S.; Cui, Y., Efficient electrocatalytic $\mathrm{CO}_{2}$ reduction on a three-phase interface. Nat. Catal. 2018, 1 (8), 592600.

13. Mariano, R. G.; McKelvey, K.; White, H. S.; Kanan, M. W., Selective increase in $\mathrm{CO}_{2}$ electroreduction activity at grain-boundary surface terminations. Science 2017, 358 (6367), 11871191.

14. Kuhl, K. P.; Hatsukade, T.; Cave, E. R.; Abram, D. N.; Kibsgaard, J.; Jaramillo, T. F., Electrocatalytic Conversion of Carbon Dioxide to Methane and Methanol on Transition Metal Surfaces. J. Am. Chem. Soc. 2014, 136 (40), 14107-14113.

15. Rahaman, M.; Dutta, A.; Zanetti, A.; Broekmann, P., Electrochemical Reduction of $\mathrm{CO}_{2}$ into Multicarbon Alcohols on Activated Cu Mesh Catalysts: An Identical Location (IL) Study. ACS Catal. 2017, 7 (11), 7946-7956. 
16. Hori, Y.; Murata, A.; Takahashi, R.; Suzuki, S., Enhanced Formation of Ethylene and Alcohols at Ambient Temperature and Pressure in Electrochemcial Reduction of Carbondioxide at a Copper Electrode. J. Chem. Soc., Chem. Commun. 1988, (1), 17-19.

17. Ma, S.; Sadakiyo, M.; Luo, R.; Heima, M.; Yamauchi, M.; Kenis, P. J. A., One-Step Electrosynthesis of Ethylene and Ethanol from CO2 in an Alkaline Electrolyzer. J. Power Sources 2016, 301, 219228.

18. Ren, D.; Deng, Y. L.; Handoko, A. D.; Chen, C. S.; Malkhandi, S.; Yeo, B. S., Selective Electrochemical Reduction of Carbon Dioxide to Ethylene and Ethanol on Copper(I) Oxide Catalysts. ACS Catal. 2015, 5 (5), 2814-2821.

19. Hori, Y.; Kikuchi, K.; Suzuki, S., Production of $\mathrm{CO}$ and $\mathrm{CH}_{4}$ in Electrochemical Reduction of $\mathrm{CO}_{2}$ at Metal-Electrodes in Aqueous Hydrogencarbonate Solution. Chem. Lett. 1985, 14 (11), 1695-1698.

20. Dufek, E. J.; Lister, T. E.; McIlwain, M. E., Bench-scale electrochemical system for generation of CO and syn-gas. J. Appl. Electrochem. 2011, 41 (6), 623-631.

21. Hansen, H. A.; Varley, J. B.; Peterson, A. A.; Norskov, J. K., Understanding Trends in the Electrocatalytic Activity of Metals and Enzymes for $\mathrm{CO}_{2}$ Reduction to CO. J. Phys. Chem. Lett. 2013, 4 (3), 388-392.

22. Verdaguer-Casadevall, A.; Li, C. W.; Johansson, T. P.; Scott, S. B.; McKeown, J. T.; Kumar, M.; Stephens, I. E. L.; Kanan, M. W.; Chorkendorff, I., Probing the Active Surface Sites for CO Reduction on Oxide-Derived Copper Electrocatalysts. J. Am. Chem. Soc. 2015, 137 (31), 9808-9811.

23. Mistry, H.; Choi, Y. W.; Bagger, A.; Scholten, F.; Bonifacio, C. S.; Sinev, I.; Divins, N. J.; Zegkinoglou, I.; Jeon, H. S.; Kisslinger, K.; Stach, E. A.; Yang, J. C.; Rossmeisl, J.; Roldan Cuenya, B., Enhanced Carbon Dioxide Electroreduction to Carbon Monoxide over Defect-Rich PlasmaActivated Silver Catalysts. Angew. Chem. Int. Ed. 2017, 56 (38), 11394-11398.

24. Li, J.; He, Y.; Tan, L.; Zhang, P.; Peng, X.; Oruganti, A.; Yang, G.; Abe, H.; Wang, Y.; Tsubaki, N., Integrated tuneable synthesis of liquid fuels via Fischer-Tropsch technology. Nat. Catal. 2018, 1, 787-793.

25. Haas, T.; Krause, R.; Weber, R.; Demler, M.; Schmid, G., Technical photosynthesis involving $\mathrm{CO}_{2}$ electrolysis and fermentation. Nat. Catal. 2018, 1 (1), 32-39.

26. Li, Y.; Cui, F.; Ross, M. B.; Kim, D.; Sun, Y.; Yang, P., Structure-Sensitive $\mathrm{CO}_{2}$ Electroreduction to Hydrocarbons on Ultrathin 5-fold Twinned Copper Nanowires. Nano Lett. 2017, 17 (2), 1312-1317.

27. Gawande, M. B.; Goswami, A.; Felpin, F. X.; Asefa, T.; Huang, X.; Silva, R.; Zou, X.; Zboril, R.; Varma, R. S., $\mathrm{Cu}$ and $\mathrm{Cu}$-Based Nanoparticles: Synthesis and Applications in Catalysis. Chem. Rev. 2016, 116 (6), 3722-3811.

28. Aditya, T.; Jana, J.; Singh, N. K.; Pal, A.; Pal, T., Remarkable Facet Selective Reduction of 4Nitrophenol by Morphologically Tailored (111) Faceted $\mathrm{Cu}_{2} \mathrm{O}$ Nanocatalyst. ACS Omega 2017, 2 (5), 1968-1984.

29. Xi, Z.; Li, J.; Su, D.; Muzzio, M.; Yu, C.; Li, Q.; Sun, S., Stabilizing CuPd Nanoparticles via CuPd Coupling to $\mathrm{WO}_{2.72}$ Nanorods in Electrochemical Oxidation of Formic Acid. J. Am. Chem. Soc. 2017, 139 (42), 15191-15196.

30. Yin, Z.; Gao, D.; Yao, S.; Zhao, B.; Cai, F.; Lin, L.; Tang, P.; Zhai, P.; Wang, G.; Ma, D.; Bao, X., Highly selective palladium-copper bimetallic electrocatalysts for the electrochemical reduction of $\mathrm{CO}_{2}$ to CO. Nano Energy 2016, 27, 35-43.

31. Menard, L. D.; Xu, F. T.; Nuzzo, R. G.; Yang, J. C., Preparation of TiO2-supported Au nanoparticle catalysts from a $\mathrm{Au}-13$ cluster precursor: Ligand removal using ozone exposure versus a rapid thermal treatment. J. Catal. 2006, 243 (1), 64-73. 
32. Gao, D.; Scholten, F.; Roldan Cuenya, B., Improved $\mathrm{CO}_{2}$ Electroreduction Performance on PlasmaActivated Cu Catalysts via Electrolyte Design: Halide Effect. ACS Catal. 2017, 7 (8), 5112-5120.

33. Mistry, H.; Varela, A. S.; Bonifacio, C. S.; Zegkinoglou, I.; Sinev, I.; Choi, Y. W.; Kisslinger, K.; Stach, E. A.; Yang, J. C.; Strasser, P.; Roldan Cuenya, B., Highly selective plasma-activated copper catalysts for carbon dioxide reduction to ethylene. Nat. Commun. 2016, 7, 12123.

34. Handoko, A. D.; Ong, C. W.; Huang, Y.; Lee, Z. G.; Lin, L.; Panetti, G. B.; Yeo, B. S., Mechanistic Insights into the Selective Electroreduction of Carbon Dioxide to Ethylene on $\mathrm{Cu}_{2} \mathrm{O}$-Derived Copper Catalysts. J. Phys. Chem. C 2016, 120 (36), 20058-20067.

35. Le, M.; Ren, M.; Zhang, Z.; Sprunger, P. T.; Kurtz, R. L.; Flake, J. C., Electrochemical Reduction of $\mathrm{CO}_{2}$ to $\mathrm{CH}_{3} \mathrm{OH}$ at Copper Oxide Surfaces. J. Electrochem. Soc. 2011, 158 (5), E45-E49.

36. Wang, B.; Wang, Y.; Li, J.; Guo, X.; Bai, G.; Tong, X.; Jin, G.; Guo, X., Photocatalytic Sonogashira reaction over silicon carbide supported $\mathrm{Pd}-\mathrm{Cu}$ alloy nanoparticles under visible light irradiation. Catal. Sci. Technol. 2018, 8 (13), 3357-3362.

37. McMahon, R. A.; Smith, M. P.; Seffen, K. A.; Voelskow, M.; Anwand, W.; Skorupa, W., Flashlamp annealing of semiconductor materials-Applications and process models. Vacuum 2007, 81 (10), 1301-1305.

38. Qin, G; Watanabe, A.; Tsukamoto, H.; Yonezawa, T, Copper film prepared from copper fine particle paste by laser sintering at room temperature: Influences of sintering atmosphere on the morphology and resistivity. Jpn. J. Appl. Phys. 2014, 53 (9), 096501.

39. Lim, H. S.; Kim, S. J.; Jang, H. W.; Lim, J. A., Intense pulsed light for split-second structural development of nanomaterials. J. Mater. Chem. C 2017, 5 (29), 7142-7160.

40. Troughton, J.; Carnie, M. J.; Davies, M. L.; Charbonneau, C.; Jewell, E. H.; Worsley, D. A.; Watson, T. M., Photonic flash-annealing of lead halide perovskite solar cells in $1 \mathrm{~ms}$. J. Mater. Chem. A 2016, 4 (9), 3471-3476.

41. Hori, Y.; Takahashi, I.; Koga, O.; Hoshi, N., Electrochemical reduction of carbon dioxide at various series of copper single crystal electrodes. J. Mol. Catal. A: Chem. 2003, 199 (1-2), 39-47.

42. Montoya, J. H.; Shi, C.; Chan, K.; Nørskov, J. K., Theoretical Insights into a CO Dimerization Mechanism in $\mathrm{CO}_{2}$ Electroreduction. J. Phys. Chem. Lett. 2015, 6 (11), 2032-2037.

43. Takahashi, I.; Koga, O.; Hoshi, N.; Hori, Y., Electrochemical reduction of $\mathrm{CO}_{2}$ at copper single crystal $\mathrm{Cu}(\mathrm{S})-\mathrm{n}(111) \times(111)$ and $\mathrm{Cu}(\mathrm{S})-\mathrm{n}(110) \times(100)$ electrodes. J. Electroanal. Chem. 2002, 533 (1-2), 135-143.

44. Mourdikoudis, S.; Liz-Marzán, L. M., Oleylamine in Nanoparticle Synthesis. Chem. Mater. 2013, 25 (9), 1465-1476.

45. Yang, H. J.; He, S. Y.; and Tuan, H. Y., Self-Seeded Growth of Five-Fold Twinned Copper Nanowires: Mechanistic Study, Characterization, and SERS Applications. Langmuir 2014, 30 (2), $602-610$.

46. Guo, H.; Chen, Y.; Ping, H.; Jin, J.; Peng, D. L., Facile Synthesis of Cu and Cu@Cu-Ni Nanocubes and Nanowires in Hydrophobic Solution in the Presence of Nickel and Chloride Ions. Nanoscale 2013, 5 (6), 2394-2402.

47. da Silva, R. R.; Yang, M.; Choi, S.-I.; Chi, M.; Luo, M.; Zhang, C.; Li, Z.-Y.; Camargo, P. H. C.; Lima Ribeiro, S. J.; Xia, Y., Facile Synthesis of Sub-20 nm Silver Nanowires through a BromideMediated Polyol Method. ACS Nano 2016, 10 (8), 7892-7900.

48. Guo, H.; Chen, Y.; Cortie, M. B.; Liu, X.; Xie, Q.; Wang, X.; Peng, D. L., Shape-selective formation of monodisperse copper nanospheres and nanocubes via disproportionation reaction route and their optical properties. J. Phys. Chem. C 2014, 118 (8), 9801-9808. 
49. Guo, H.; Buchel, M.; Li, X.; Wackerlin, A.; Chen, Q.; Burgert, I., Dictating anisotropic electric conductivity of a transparent copper nanowire coating by the surface structure of wood. $J R S o c$ Interface 2018, 15 (142), 20170864.

50. Jin, M.; He, G.; Zhang, H.; Zeng, J.; Xie, Z.; Xia, Y., Shape-Controlled Synthesis of Copper Nanocrystals in an Aqueous Solution with Glucose as a Reducing Agent and Hexadecylamine as a Capping Agent. Angew. Chem. Int. Ed. 2011, 50 (45), 10560-10564.

51. Kim, M. J.; Alvarez, S.; Chen, Z.; Fichthorn, K. A.; Wiley, B. J., Single-Crystal Electrochemistry Reveals Why Metal Nanowires Grow. J. Am. Chem. Soc. 2018, 140 (44), 14740-14746.

52. Broekmann, P.; Wilms, M.; Kruft, M.; Stuhlmann, C.; Wandelt, K., In-situ STM investigation of specific anion adsorption on $\mathrm{Cu}(111)$. J. Electroanal. Chem. 1999, 467 (1-2), 307-324.

53. Polewska, W.; Behm, R. J.; Magnussen, O. M., In-situ video-STM studies of Cu electrodeposition on $\mathrm{Cu}(100)$ in $\mathrm{HCl}$ solution. Electrochim. Acta 2003, 48 (20-22), 2915-2921.

54. Magnussen, O. M., Ordered Anion Adlayers on Metal Electrode Surfaces. Chem. Rev. 2002, 102 (3), 679-726.

55. Huemann, S.; Hai, N. T. M.; Broekmann, P.; Wandelt, K.; Zajonz, H.; Dosch, H.; Renner, F., X-ray Diffraction and STM Study of Reactive Surfaces under Electrochemical Control: $\mathrm{Cl}$ and I on Cu(100). J. Phys. Chem. B 2006, 110 (49), 24955-24963.

56. Huynh, T. M. T.; Hai, N. T. M.; Broekmann, P., Quasi-Reversible Interaction of MPS and Chloride on $\mathrm{Cu}(100)$ Studied by In Situ STM. J. Electrochem. Soc. 2013, 160 (12), D3063-D3069.

57. Wilms, M.; Broekmann, P.; Kruft, M.; Stuhlmann, C.; Wandelt, K., STM investigation of step orientation and surface dynamics of $\mathrm{Cu}(111)$ in hydrochloric acid electrolyte. Appl. Phys. A 1998, 66, S473-S475.

58. Wilms, M.; Broekmann, P.; Kruft, M.; Park, Z.; Stuhlmann, C.; Wandelt, K., STM investigation of specific anion adsorption on $\mathrm{Cu}(111)$ in sulfuric acid electrolyte. Surf. Sci. 1998, 402, 83-86.

59. Schouten, K. J. P.; Kwon, Y.; van der Ham, C. J. M.; Qin, Z.; Koper, M. T. M., A New Mechanism for the Selectivity to C1 and C2 Species in the Electrochemical Reduction of Carbon Dioxide on Copper Electrodes. Chem. Sci. 2011, 2 (10), 1902-1909.

60. Calle-Vallejo, F.; Koper, M. T. M., Theoretical Considerations on the Electroreduction of CO to C2 Species on $\mathrm{Cu}(100)$ Electrodes. Angew. Chem. Int. Ed. 2013, 52 (28), 7282-7285.

61. Hori, Y.; Takahashi, I.; Koga, O.; Hoshi, N., Selective Formation of C2 Compounds from Electrochemical Reduction of $\mathrm{CO} 2$ at a Series of Copper Single Crystal Electrodes. J. Phys. Chem. B 2002, $106(1), 15-17$.

62. Baturina, O. A.; Lu, Q.; Padilla, M. A.; Xin, L.; Li, W.; Serov, A.; Artyushkova, K.; Atanassov, P.; $\mathrm{Xu}$, F.; Epshteyn, A.; Brintlinger, T.; Schuette, M.; Collins, G. E., $\mathrm{CO}_{2}$ Electroreduction to Hydrocarbons on Carbon-Supported Cu Nanoparticles. ACS Catal. 2014, 4 (10), 3682-3695.

63. Lee, S. Y.; Jung, H.; Kim, N.-K.; Oh, H.-S.; Min, B. K.; Hwang, Y. J., Mixed Copper States in Anodized $\mathrm{Cu}$ Electrocatalyst for Stable and Selective Ethylene Production from $\mathrm{CO}_{2}$ Reduction. $J$. Am. Chem. Soc. 2018, 140 (28), 8681-8689.

64. Frese, K. W., Electrochemical Reduction of $\mathrm{CO}_{2}$ at Intentionally Oxidized Copper Electrodes. $J$. Electrochem. Soc. 1991, 138 (11), 3338-3344.

65. Li, C. W.; Kanan, M. W., $\mathrm{CO}_{2}$ Reduction at Low Overpotential on Cu Electrodes Resulting from the Reduction of Thick $\mathrm{Cu}_{2} \mathrm{O}$ Films. J. Am. Chem. Soc. 2012, 134 (17), 7231-7234.

66. Grosse, P.; Gao, D.; Scholten, F.; Sinev, I.; Mistry, H.; Roldan Cuenya, B., Dynamic Changes in the Structure, Chemical State and Catalytic Selectivity of $\mathrm{Cu}$ Nanocubes during $\mathrm{CO}_{2}$ Electroreduction: Size and Support Effects. Angew. Chem. Int. Ed. 2018, 57 (21), 6192-6197. 
67. Hori, Y.; Murata, A.; Takahashi, R., Formation of Hydrocarbons in the Electrochemical Reduction of Carbondioxide at a Copper Electrode in Aqueous Solution J. Chem. Soc., Faraday Trans. 1 1989, 85 (8), 2309-2326.

68. Akhade, S. A.; Luo, W.; Nie, X.; Bernstein, N. J.; Asthagiri, A.; Janik, M. J., Poisoning effect of adsorbed $\mathrm{CO}$ during $\mathrm{CO}_{2}$ electroreduction on late transition metals. Phys. Chem. Chem. Phys. 2014, 16 (38), 20429-20435.

69. DeWulf, D. W.; Jin, T.; Bard, A. J., Electrochemical and surface studies of carbon-dioxide reduction to methane and ethylene at copper electrodes in aqueous-solutions. J. Electrochem. Soc. 1989, 136 (6), 1686-1691.

70. Nie, X.; Esopi, M. R.; Janik, M. J.; Asthagiri, A., Selectivity of $\mathrm{CO}_{2}$ Reduction on Copper Electrodes: The Role of the Kinetics of Elementary Steps. Angew. Chem. Int. Ed. 2013, 52 (9), 2459-2462.

\section{Figure Captions}

Figure 1: Schematic representations and top-down optical micrographs of individual steps followed for the preparation of the $\mathrm{Cu}-\mathrm{MMC}$ (copper metal membrane catalyst) on the glassy carbon support.

Figure 2: White-light interferometric analysis of the $\mathrm{Cu}-\mathrm{MMC}$ after the photonic curing $\left(5.9 \mathrm{~kW} \mathrm{~cm}^{-2}\right.$; $50 \mu \mathrm{s})$; a) - b) Representative location in the center of the Cu-MMC; c) Representative location at the edge of the $\mathrm{Cu}-\mathrm{MMC}$; d) Cross-sectional line-scan indicated in c).

Figure 3: a) Top-down SEM inspection of the Cu-MMC after the photonic curing; b) HR-TEM micrograph of an individual $\mathrm{Cu}-\mathrm{NW}$; c) Selective area electron diffraction (SAED) analysis obtained from an individual $\mathrm{Cu}-\mathrm{NW}$ after the photonic curing; d) Schematic drawing showing the $\mathrm{Cu}-\mathrm{NW}$ before (left panel) and after (right panel) the activation treatment.

Figure 4: a) $\mathrm{CO}_{2} \mathrm{RR}$ product distributions from various $\mathrm{Cu}-\mathrm{MMCs}$ photonically cured using a constant irradiance of $5.9 \mathrm{~kW} \mathrm{~cm}^{-2}$ but varying pulse times; the $\mathrm{CO}_{2} \mathrm{RRs}$ were carried out for $1 \mathrm{~h}$ at -1.1 $\mathrm{V}$ vs RHE in each case; b) Potential depending $\mathrm{CO}_{2} \mathrm{RR}$ product distributions derived from the optimum catalyst at $50 \mu$ s curing time.

Figure 5: $\mathrm{CO}_{2} \mathrm{RR}$ product distribution at $-1.1 \mathrm{~V}$ vs RHE ( $1 \mathrm{~h}$ electrolysis) derived from catalysts treated by various procedures for the removal of the surfactant. For comparison purposes also the results from the as-prepared (AP) sample are shown.

Figure 6: a) XPS analyses of the $\mathrm{Cu}-\mathrm{NW}$ assemblies carried out after applying different activation treatments (for details see text). The ratio of the integrated $\mathrm{N} 1 s$ and $\mathrm{Cu} 2 p_{3 / 2}$ emissions serves as measure for the removal of the surfactants which preferably bind via their nitrogen functionality to the copper surface; b) Enlarged section of a) focusing on the well-performing surfactant removal treatments.

Figure 7: Optical micrographs of the $\mathrm{Cu}-\mathrm{NW}$ catalysts prior to and after $1 \mathrm{~h} \mathrm{CO}_{2} \mathrm{RR}$ at $-1.1 \mathrm{~V}$ vs RHE. Considered are the as-prepared sample, the one thermally annealed at $200{ }^{\circ} \mathrm{C}$, the ones exposed to ozone and deep UV light, and the photonically cured $\mathrm{Cu}$ catalyst.

Figure 8: Long-term $(110 \mathrm{~h})$ continuous $\mathrm{CO}_{2}$ electrolysis experiment carried out over the photonically cured $\mathrm{Cu}-\mathrm{MMC}$ at $-1.1 \mathrm{~V}$ vs RHE (note that the product detection by online gaschromatograpphy was not carried out over the full electrolysis time).

Figure 9: Proposed reaction mechanism of ethylene formation on Cu catalysts. 

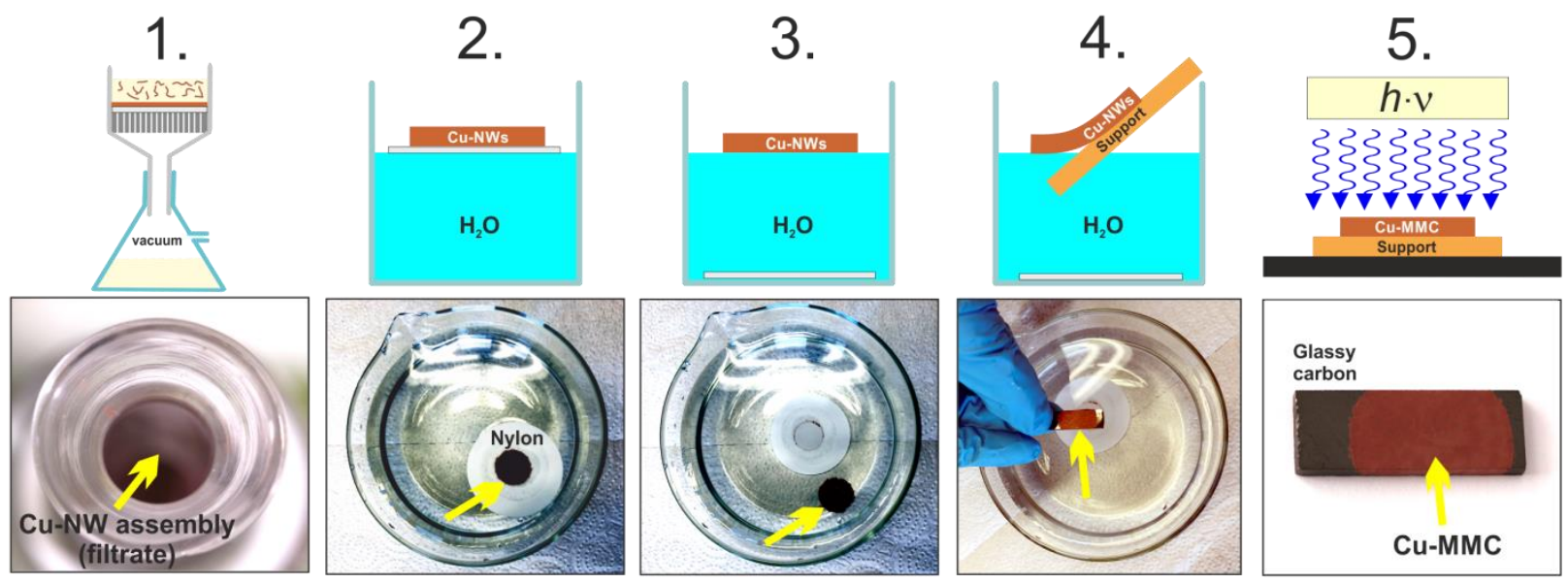

Fig. 1 

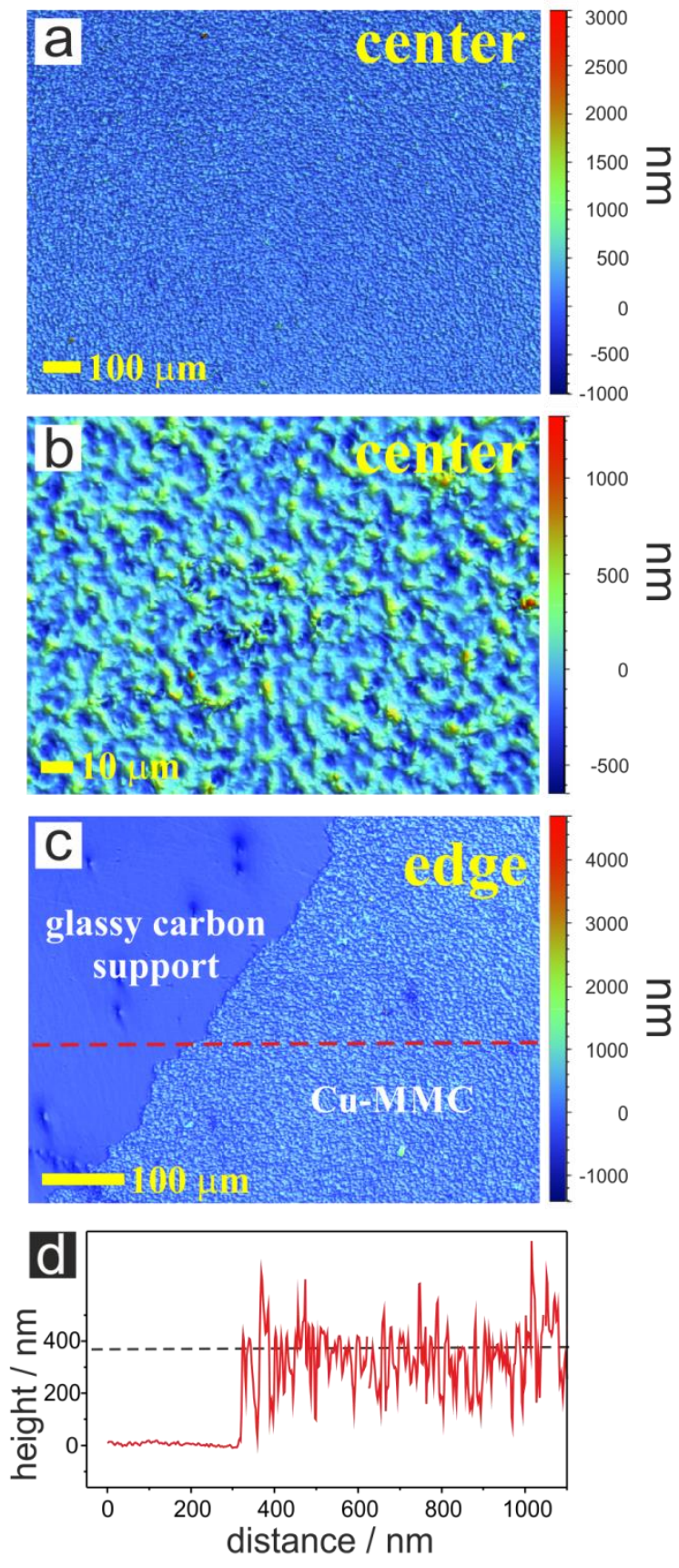

Fig. 2 

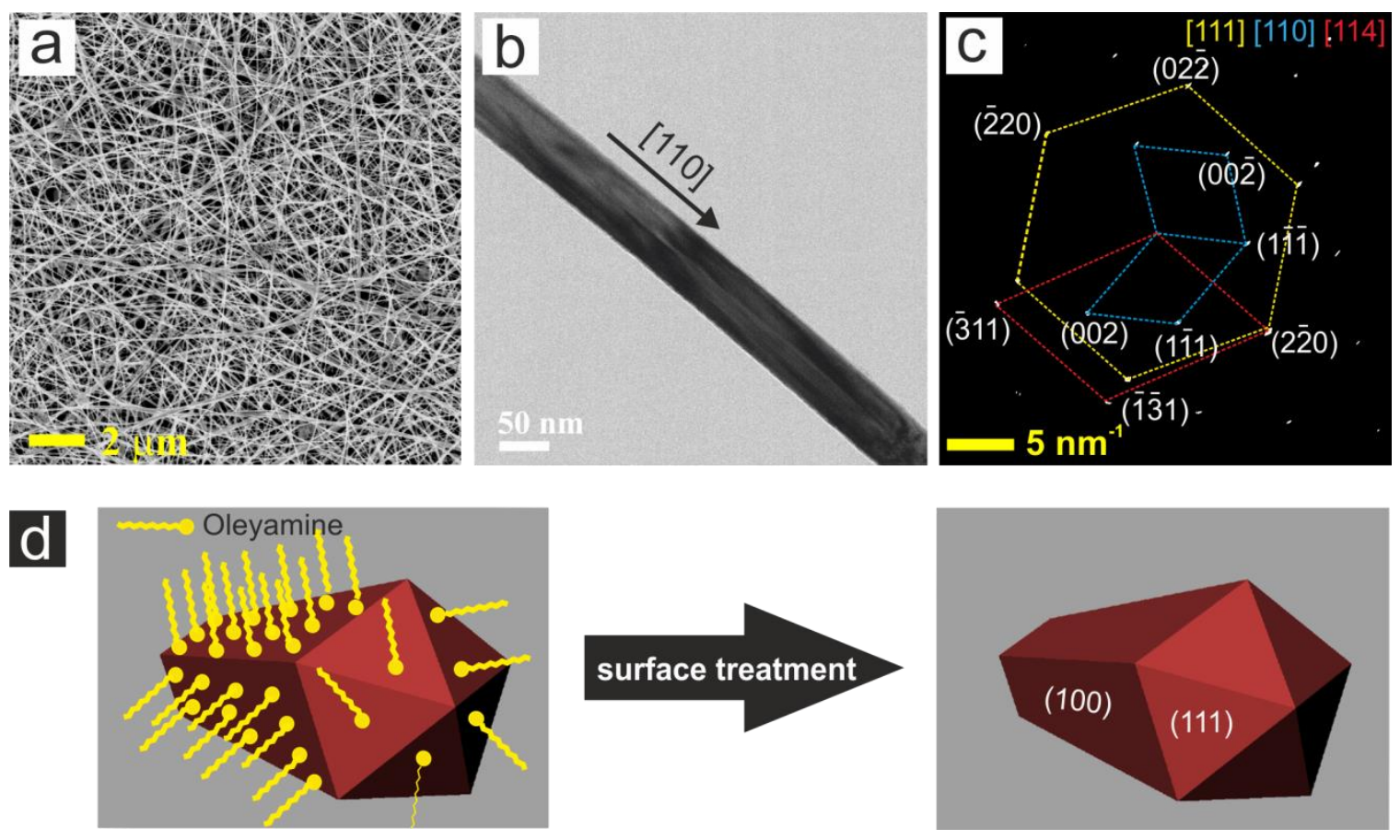

Fig. 3 

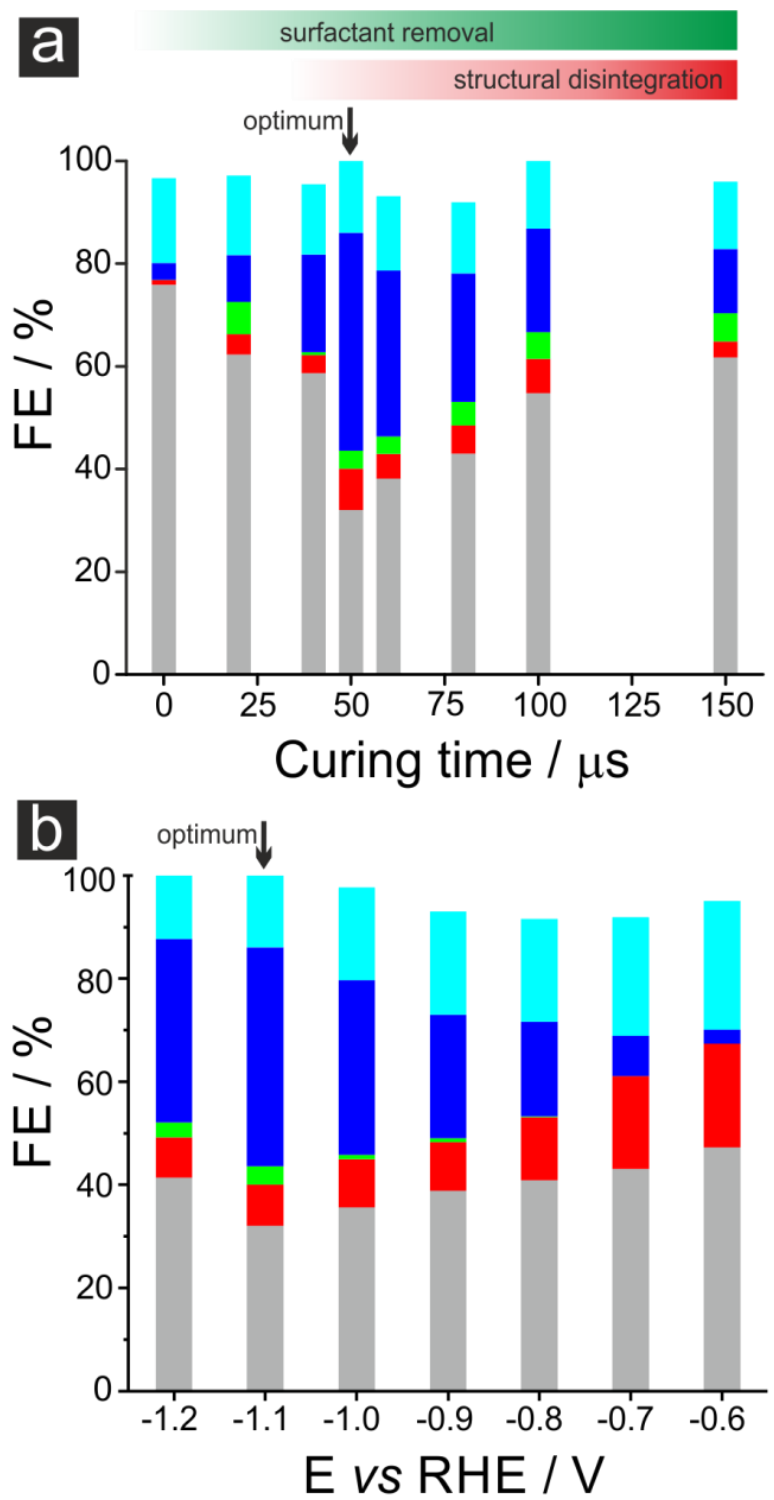

$\begin{array}{ll}\mathrm{H}_{2} & \mathrm{CO} \\ \mathrm{CH}_{4} & \mathrm{HCOO}^{-}\end{array}$

Fig. 4 


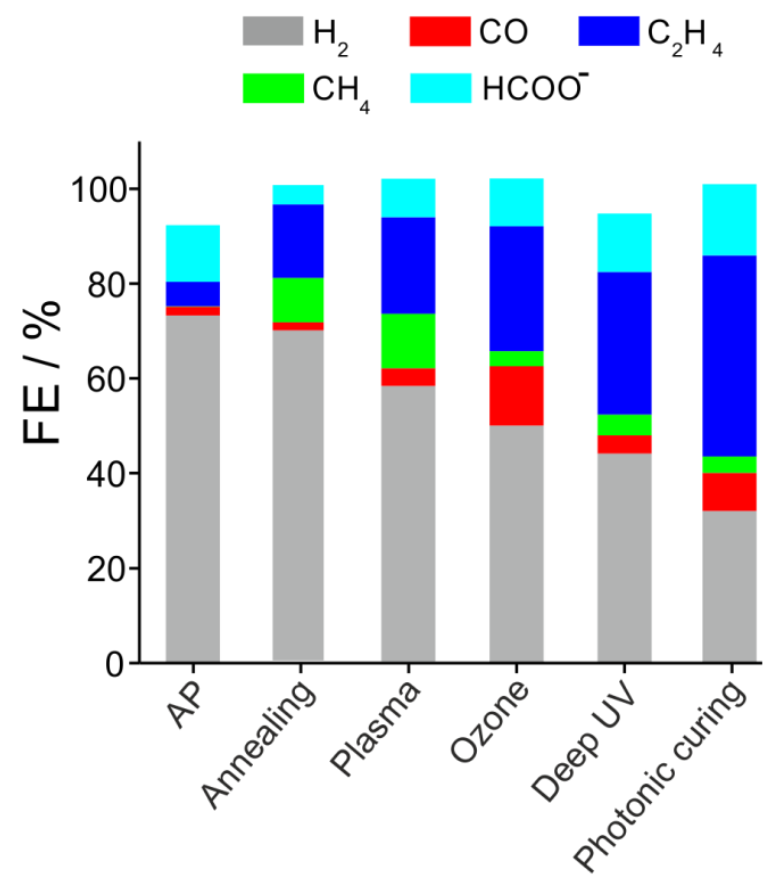

Fig. 5 

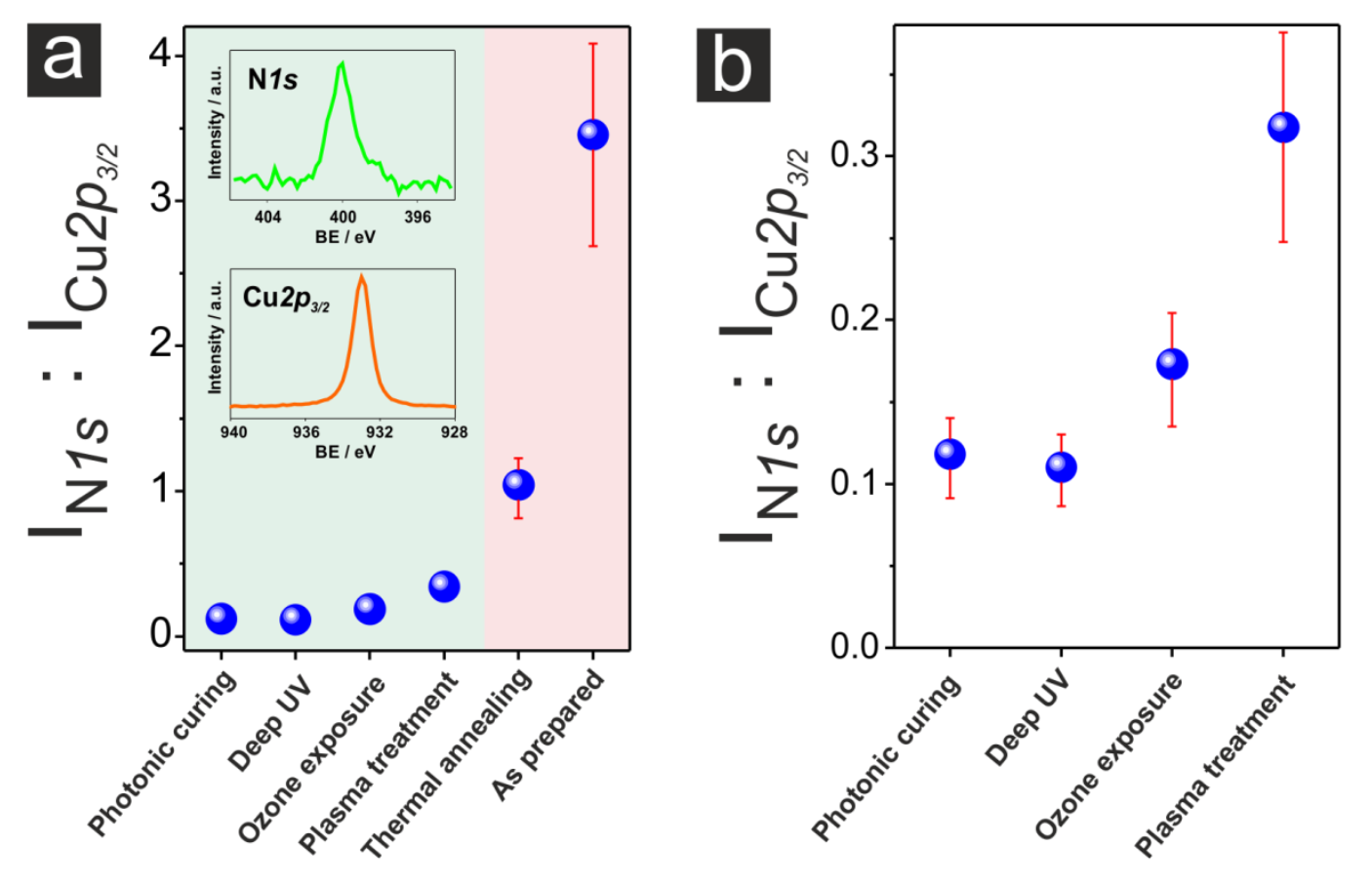

Fig. 6 

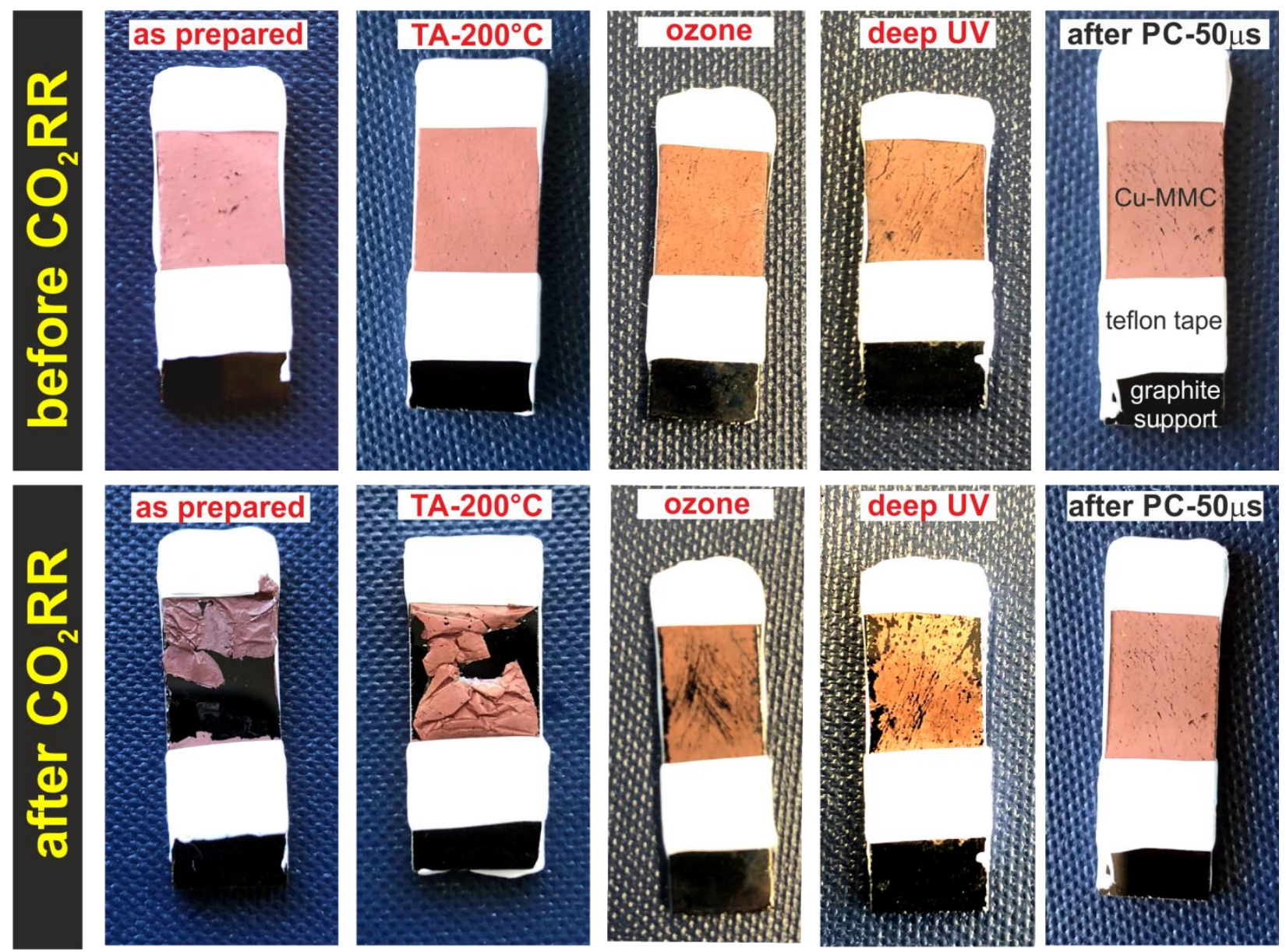

\section{Fig. 7}




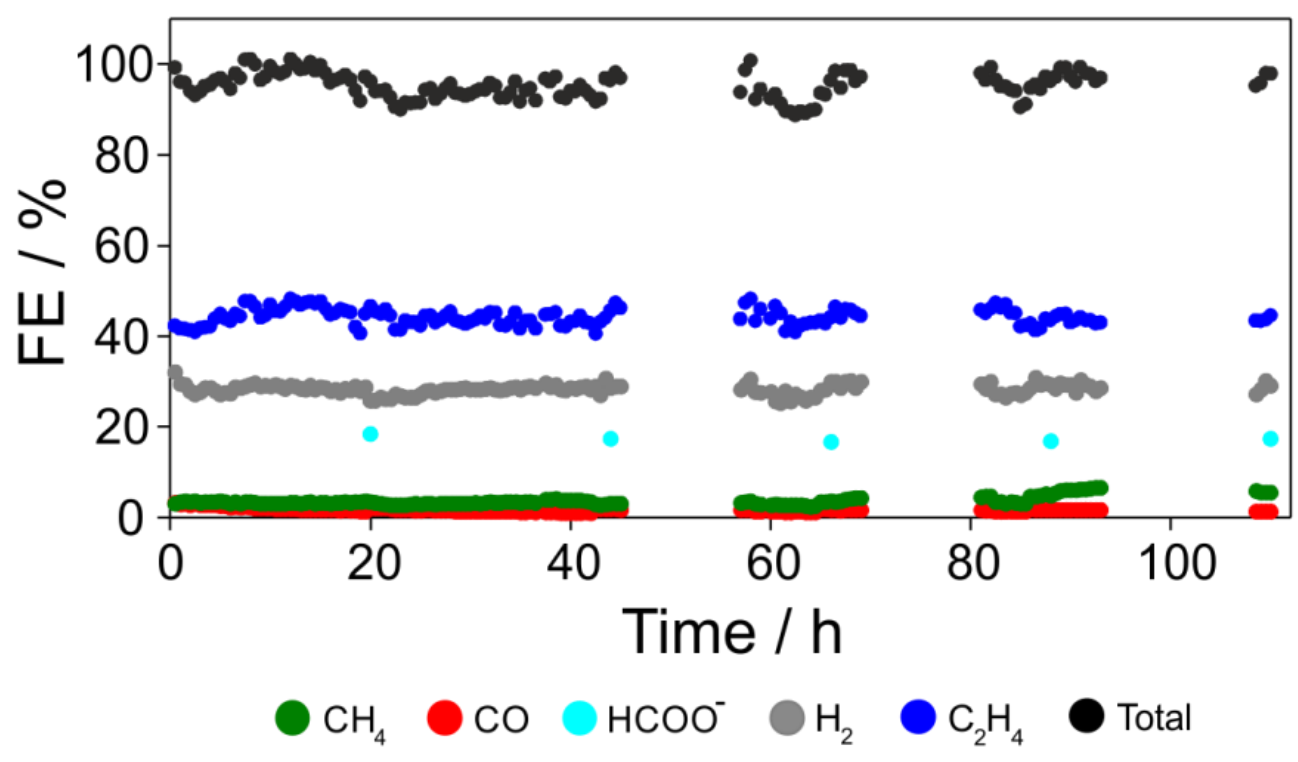

Fig. 8 


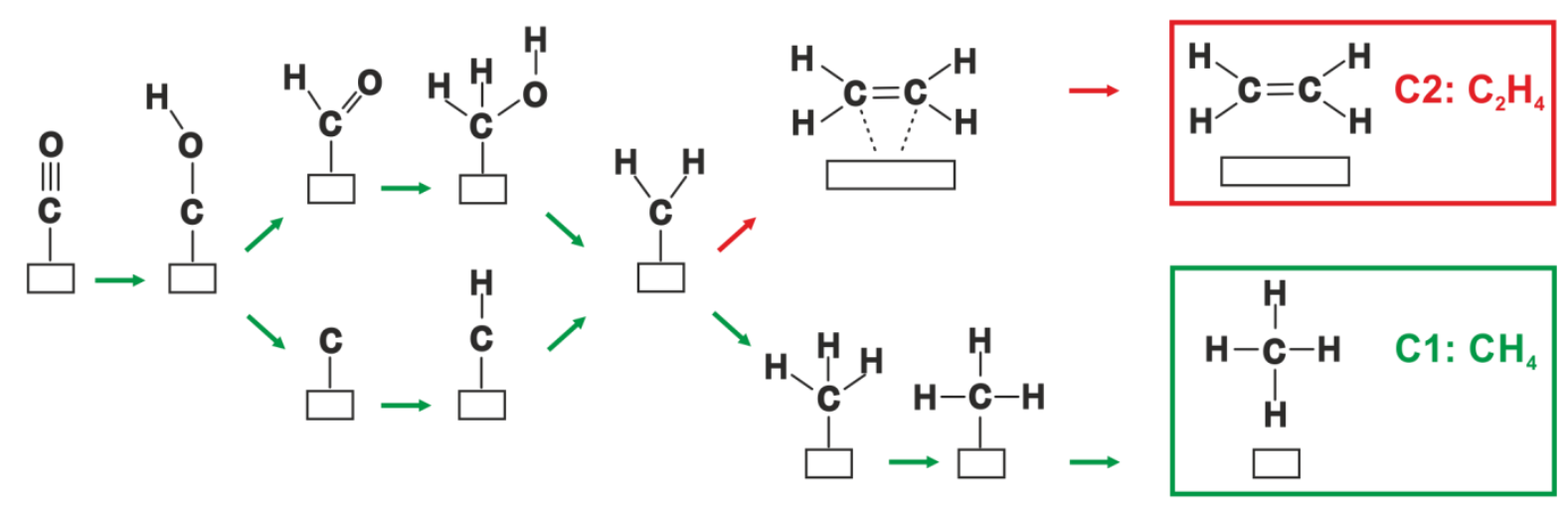

Fig. 9 